NBER WORKING PAPER SERIES

\author{
THE TIME VARIATION OF RISK AND RETURN \\ IN FOREIGN EXCHANGE MARKETS: \\ A GENERAL EQUILIBRIUM PERSPECTIVE
}

Geert Bekaert

Working Paper No. 4818

\author{
NATIONAL BUREAU OF ECONOMIC RESEARCH \\ 1050 Massachusetts Avenue \\ Cambridge, MA 02138 \\ August 1994
}

This paper has benefitted from the comments and suggestions of Tim Bollerslev, Jonas Fisher, Steve Grenadier, David Marshall, Ken Singleton, Mark Watson and the participants in seminars at Camegie-Mellon University, UBC, University of Chicago, Stanford University, U.C.L.A., University of Pennsylvania, the Wharton School, Yale University, Columbia University, New York University, INSEAD, University of Illinois, the Summer Meeting of the Econometric Society in Seattle, the Sloane School at M.I.T., the Haas School of Business at UC Berkeley and the 1993 Joint Statistical Meetings in San Francisco. Special thanks go to Robert Hodrick for his many suggestions and continuous encouragement. Financial support from a Sloan Dissertation Fellowship, an NSF-grant and the Financial Services Research Initiative of the Graduate School of Business at Stanford is gratefully acknowledged. This paper is part of NBER's research program in Asset Pricing. Any opinions expressed are those of the author and not those of the National Bureau of Economic Research.

(C) 1994 by Geert Bekaert. All rights reserved. Short sections of text, not to exceed two paragraphs, may be quoted without explicit permission provided that full credit, including (c) notice, is given to the source. 
NBER Working Paper \#4818

August 1994

\title{
THE TIME VARIATION OF RISK AND RETURN \\ IN FOREIGN EXCHANGE MARKETS: \\ A GENERAL EQUILIBRIUM PERSPECTIVE
}

\begin{abstract}
This paper investigates the statistical properties of high frequency nominal exchange rates and forward premiums in the context of a dynamic two-country general equilibrium model. Primary focus is on the persistence, variability, leptokurtosis and conditional heteroskedasticity of exchange rates and on the behavior of foreign exchange risk premiums. The model combines temporal dependencies in preferences with a transaction cost technology that generates a role for money. Agents in the economy make decisions on a weekly frequency and face shocks which display time-varying uncertainty. Simulations reveal that the model accounts for the statistical properties of exchange rate data much more accurately than previous structural models.
\end{abstract}

\author{
Geert Bekaert \\ Graduate School of Business \\ Stanford University \\ Stanford, CA 94305-5015 \\ and NBER
}




\section{INTRODUCTION}

The increasing globalization of financial markets has intensified the need to understand foreign exchange markets. A large body of empirical research bas uncovered many interesting empirical regularities characterizing foreign exchange markets. The following are four well-known stylized facts. First, the forward rate is not an unbiased predictor of the future spot rate. Second, exchange rate changes are highly variable and aearly uncorrelated. Third, forward premiums, which predict exchange rate changes, are less variable and are highly persistent. Fourth, exchange rates display substantial serial dependence in their second moments. ${ }^{1}$ Furthermore, conditional heteroskedasticity in exchange rates is only detectable at high frequencies. At the monthly or quarterly frequency, it is no longer statistically significant (Baillie and Bollerslev (1989)). As time-varying second moments imply leptokurtic unconditional distributions, conditional heteroskedasticity may also be an important source behind the fat tails in unconditional distributions of exchange rate changes. Exchange rate cbanges are the main component of forward market returns. As is well-known, these returns are an imporant component of the return on any foreign currency denominated uncovered investment. The first and fourth empirical facts imply that conditional means and variances of forward market returns vary through time.

This paper develops a two country monetary general equilibrium model that can potentially generate such empirical phenomena. The model builds on the representative agent framework of Lucas (1978). The only friction in the model is the presence of transaction costs which give rise to money being valued in equiltbrium and induces variable velocities. Exchange rate movements reflect changes in relative money supplies, velocities and outputs whereas time-variation in expected returns reflects time-varying rewards to consumption and inflation risk.

Previous attempts at explaining the significant rejection of the unbiasedness hypothesis within a fully parameterized general equilibrium model have failed dramatically. ${ }^{2}$ The model developed here bas several features that are likely to improve its performance with respect to the empirical puzzles. First, 
I explicitly introduce time-variation in the conditional variances of the market fundamentals. Second, I assume a weekly decision interval for the economic agents.' Third, various forms of temporally dependent preferences are explored as in Ferson and Constantinides (1991) and Heaton (1993).

The main novelty of the model here is the combination of time-varying uncertainty in the fundamentals with a high frequency decision interval for the agents. It is well-known that movements in conditional variances of market fundamentals cause movements in both expected returns and conditional variances of asset prices. However, there exists little evidence of time-varying conditional variances in market fundamentals such as monetary shocks and consumption at the monthly or quarterly frequencies at which they are usually measured. As I will explain in more detail below, this might be due to temporal aggregation which causes time-variation in conditional variances to disappear. The same phenomenon causes conditional heteroskedasticity in exchange rates to be much weaker when exchange rates are sampled at lower frequencies.

The discrete-time framework simplifies the introduction of a rich time-nonseparable preference structure. Backus, Gregory and Telmer (1993) and Bansal, Gallant, Hussey and Tauchen (1993) also examine the effects of nonseparabilities in an international model but their preference structure is much less general than the one used in this paper. Backus, Gregory and Telmer (1993) for instance are successful in generating more variable forward market risk premiums by allowing strong habit persistence. However, this comes at the cost of unrealistic values for the autocorrelation structure of forward premiums. By incorporating both durability of consumption and habit persistence of a long run nature, I am able to generate more realistic variability and correlation patterns for exchange rates and forward premiums than previous structural models.

The model allows characterization of the endogenous joint distribution of forward market returns, exchange rates and forward premiums as a function of the model's structural parameters and the law of motion of the stochastic forcing variables. I explore the implications of the model through several 
simulation experiments. To impose discipline on the simulations, 1 estimate the conditional mean parameters and unconditional second moments of the weekly law of motion for the forcing processes from quarterly data on consumption and money growth in the U.S. and the U.K.. The embedded temporal aggregation problem is resolved relying on results in Bekaert (1992).

The simulation experiments are designed to accomplish two goals. First, the generality of the model allows the comparison of the model's predictions for the moments of exchange rate changes, forward premiums and risk premiums to the predictions of simpler models. In particular, I start from a simple cash-in-advance (CIA) model with time-additive preferences, and show the effects of adding transaction costs, durability, habit persistence and time-varying uncertainty in the fundamentals. The importance of time-varying uncertainty in the fundamentals driving foreign exchange markets was stressed by Hodrick (1989), but the jdea had surfaced before in the equity pricing literature. Poterba and Summers (1986) derive a positive relationship between the persistence of stock market volatility and stock prices in a simple partial equilibrium model for stock prices whereas Abel (1988) generalizes their results to a general equilibrium Lucas-type (1978) model. He finds that the effect of dividend riskiness on stock prices can be in either direction whereas the magnitude of the effect is an increasing function of the persistence of dividend volatility. I investigate the effect on endogenous moments of both the persistence and the leptokurtic nature of conditional variance shocks in the fundamentals.

The second goal of the paper is to examine the effects of various non-linearities in the economic environment on heteroskedasticity and leptokurtosis in exchange rates and forward premiums. Most research to date has attempted to model these non-linear patterns with purely statistical models. This is one of the first papers to address how volatility clustering of financial returns can arise endogenously in an equilibrium model. ${ }^{4}$

To anticipate the results, the simulations reveal that the model performs very well along a number of dimensions. When consumption exhibits short-run substitutability and long-run complementarity, the 
model comes close to matching the autocorrelation structure of the forward premium in the data. The risk premium is many times more variable than in a model with time-additive preferences. The introduction of modestly persistent time-variation in the second moments of the fundamentals at the weekly level, consistent with the lack of heteroskedasticity in these processes at the quarterly level, generates substantial beteroskedasticity and fat tails in both exchange rates and forward premiums. Heteroskedasticity in the forcing processes also substantially increases the variability of the risk premium. without worsening the fit of the model much along other dimensions. Yet, the variability of the risk premium does not exceed that of the forward premium as is implied by the data.

The paper is organized as follows. The first section briefly re-examines the empirical evidence for dollar returns in the Europound market. The second section of the paper presents the model in detail." The third section of the paper discusses the solution procedure and choice of parameters. The fourth section contains the simulation results. In the conclusions of the paper, 1 point out some possible generalizations of the model.

\section{EMIPIRICAL REGULARITIES}

Definition of variables

The data set consists of weekly observations on dollar-pound rates and one- and three-month Eurodollar and Europound interest rates for the 1975-1990 period, but the empirical results are representative for other major currencies as well. The data are described in more detail in the data appendix. Asterisks indicate Britisb pound variables. Consider an investment in a Europound deposit which carries an interest rate of $i_{i \perp}^{*}$, with $n$ the maturity in weeks. The bolding period considered in this paper is one month (a 30 day contract), and one month is approximated by 4 weeks in subsequent analysis." Let $S_{1}$ be the dollar price of a pound. The uncovered dollar return on a continuously compounded Europound investment is $\left(S_{1+2} / S\right) \exp \left(i_{i, 2}^{*}\right)$. The rate of return is then $\left[\Delta s_{1+2,}+i_{1,2}^{*}\right.$, where 
$\Delta s_{1, \ldots}=\ln \left(S_{1},\right) \cdot \ln \left(S_{)}\right)$. Hence, the excess rate of return over a Eurodollar deposit is given by:

$r_{1+a s}=\left[\Delta s_{1+a}+i_{i, 2}-i_{2}\right]$. This return also corresponds to the difference between the future spoi rate and the current forward rate. To see this, la $f_{p_{6}}=\ln \left(F_{W}\right)-\ln \left(S_{J}\right)$, where $F_{W}$ is the forward rate for a n-week contract in dollars per pound. Consider covered interest rate parity in continuously compounded form:

$$
f_{\varphi}=i_{0}-i_{i}
$$

It follows that $r_{1+e}=\left[\ln \left(S_{1+1}\right)-\ln \left(F_{5}\right)\right]$ and hence, $r_{1+\ldots e}$ can also be viewed as the logarithmic approximation to the return on a long forward position in the pound scaled by the forward rate, i.e. $\ln \left(S_{1+2}\right)-\ln (F)=\left(S_{1+\infty}-F_{W}\right) / F_{W}$. The ex ante return to forward for eign exchange speculation is denoted by tp:

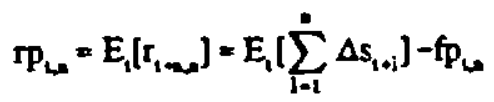

with $\Delta s$, referring to weekly exchange rate changes.

Time series properties of the variables

Means, standard deviations and autocorrelations of $\Delta s_{1}$ and $f_{p_{4}}$ are reported in Table 1, Panel A. To summarize the autocorrelation structure of the variables, I report variance ratios. The variance ralio of a stationary time series $\left\{x_{1}\right\}_{i-1}^{\top}$ for a horizon of $\mathbf{r}$ periods is defined as:

$$
v_{k}=\frac{\operatorname{var}\left(\sum_{j=\infty}^{k} x_{, . j}\right)}{(k+1) \operatorname{var}(x)}
$$

The variance ratio can be consistently estimated as:

$$
\hat{v}_{k}=1+2 \sum_{j=1}^{k}\left(1-\frac{j}{k+1}\right) \hat{p}_{j}
$$

with $\dot{\rho}_{j}$ the sample autocorrelation of order $j$ for $\left\{x_{1}\right\}_{--1}^{T}$. The variance ratio is one for a serially 
uncorrelated time series, is less than one if negative autocorrelations dominate and is greater than one if positive autocorrelations dominate.

Panel A in Table 1 also explores the presence of leptokurtosis and heteroskedasticity in the two series. To remove the serial correlation from the forward premium series, it was simply differenced. Autocorrelations and variance ratios are then computed for the squared differenced series. Under the null of conditional homoskedasticity, the autocorrelations equal zero and the variance ratios equal one.

Panel B in Table 1 focusses on cross-correlations. The cross-correlations between $\Delta s_{++1}, \Delta s_{t+3}$, $\Delta q_{1+2}, \Delta q_{1+1}$ and fp, are related to what is known as the unbiasedness issue. When future exchange rate changes are regressed onto a constant and the forward premium, the slope coefficients are typically negative rather than one." The sum of the 4 cross-correlations mentioned above times the ratio of the standard deviation of exchange rate changes to the standard deviation of the forward premium provides an estimate of this slope coefficient. The coefficient is estimated at -2.116 with a standard error of $.761 .^{7}$ The fitted value of this regression can be used to compute a lower bound to the standard deviation of the risk premium. The lower bound on risk premium volatility is estimated at $10.841 \%$ in annualized terms with a standard error of $2.847 \%$.

From these tables, several regularities emerge that a successful model should match:

(I) Exchange rate changes show some positive persistence but the autocorrelations are generally small.

On the other hand, the forward premium is very persistent. I term this regularity the "persistence puzzle".

(II) Exchange rate changes are many times more variable than the forward premium whereas the risk premium in the British pound forward market is also extremely variable. In fact, $\sigma\left(\Delta s_{+2+\infty}\right)>\sigma\left(\mathrm{rp}_{\omega}\right)$ $>\sigma\left(\mathrm{fp}_{\mathrm{L}}\right) .1$ refer to this relative variability property as the "volatility puzzle".

(III) Forward premiums and exchange rates exhibit marked positive serial dependence in their second moments and substantial leptokurtosis. Somewhat surprisingly, heteroskedasticity and leptokurtosis are 
even stronger for forward premiums than they are for exchange rate changes. The predictability of exchange rate changes by the forward premium extends to the second momeats (Panel B), but the correlations are generally weaker and less precisely measured.

\section{THE ECONOMIC ENVIRONMENT}

In this section, I describe the agents' preferences, budget constraints and the Euler equations determining important endogenous variables. I also show bow exchange rates are determined and forward contracts priced. In addition, some further intuition is given on why this model might perform better than previous models with respect to the empirical puzzles mentioned above.

\section{Description of the model}

The model analyzed in this paper is a generalization of the two country model proposed by Lucas (1982). Each country has its own money, which grows at a stocbastic rate, and its own endowment tree, which yields stochastically growing "home" or "foreign" consumption goads. Identical infinitely-lived representative agents in both countries maximize the expected discounted sum of a von NeumannMorgenstern utility function subject to a sequence of budget constraints.

To derive the budget constraint, consider the period by period problem facing the domestic representative agent. Each period, she purchases bome goods $x_{1}^{\prime}$ and foreign goods $y_{1}^{\prime}$ which are priced in the respective currencies with prices $P_{i}(i=x, y)$. The exchange rate $S_{t}$ converts the price of the foreign good into units of the home currency. Whereas in Lucas's model consumption purchases have to be financed with money, I assume that money balances diminish the transaction costs associated with buying consumption goods. In particular, let $m_{v}\left(n_{v}\right)$ be the level of home (foreign) real money balances held by the household. The transaction cost functions $\Psi^{2}\left(x_{1}^{4}, m_{1}\right)$ and $\Psi^{\prime}\left(y_{1}^{4}, n_{1}\right)$ are decreasing in own real balances and increasing in the amount of goods bought (see also Marshall (1992) and Bansal, Gallant, Hussey and Tauchen (1993)). The domestic household also chooses the level of home and foreign money balances 
$M_{1+1}^{d}$, respectively $N_{i+1}^{d}$, to be carried over to the next period and acquires asset holdings, summarized in the vector $z_{1+1}$. Asser prices are stacked in the vector $Q_{1}$. All purchases have to be made with current nominal wealth $W_{1}$, denominated in the home currency. Wealth consists of the money holdings chosen last period and the current market value of the asset holdings including stochastic payoffs (dividends) $D_{1}$. The home consumer's budget constraint is then given by":

$$
\begin{aligned}
& P_{1}^{\prime}\left(x_{1}^{d}+\Psi^{\prime}\left(x_{1}^{d}, m_{2}\right)\right)+S_{1} P_{1}^{\prime}\left(y_{1}^{d}+\Psi^{\prime}\left(y_{1}^{d}, n_{2}\right)\right)+z_{1+1}^{\prime} Q_{1}+M_{1+1}^{d}+S_{1} N_{1+1}^{d} \leq W_{1} \\
& W_{1}=z_{1}^{\prime}\left(Q_{1}+D_{j}\right)+M_{1}^{d}+S_{1} N_{1}^{d}
\end{aligned}
$$

\section{Preferences}

As in Eichenbaum and Hansen (1990), preferences are time separable over the service flow:s $s_{i}^{*}$ and s. derived from past consumption purchases of the home good $x$ and the foreign good $y$ :

$$
\mathrm{E}_{0} \sum_{i=0}^{\infty} \beta^{n} \mathrm{u}\left(\mathrm{s}_{1}{ }^{n}, \mathrm{~s}_{1}^{n}\right)
$$

Following Ferson and Constantinides (1991) and Heaton (1993), 1 assume that goods are durable and that consumers form habits over the services derived from them. Let $k_{1}^{x}$ be the stock of home consumption goods which depreciates at the rate $1-\mu_{2}$ and $h_{1}^{2}$ the habit stock defined over past service flows. I assume:

$$
\begin{aligned}
& k_{1}^{\prime}=\sum_{j=0}^{\infty} \mu_{x}^{\prime} x_{1-1}^{\prime} \\
& h_{1}^{*}=\eta_{1}\left(1-\theta_{2}\right) \sum_{j=0}^{\infty} \theta_{1}^{\prime} k_{1-1-j}^{\prime} \\
& s_{1}^{\prime}=k_{1}^{\prime}-h_{1}^{\prime \prime}
\end{aligned}
$$

Note that $\eta_{2}$ is the sum of the "habit weights", and that decreasing $\theta_{2}$ will increase habit effects at shor lags.

Nonseparabilities embedded in this preference specification are apparent from considering the 
expression for marginal utility in this context. The marginal utility derived from a purchase of the home good today is given by:

$$
m u x_{1}=E_{1}\left[\sum_{T=0}^{\infty} \beta^{\top} a_{1}=\frac{\partial u\left(S_{\left.1+r, S_{1+r}^{x}\right)}^{x}\right]}{\partial \mathrm{s}_{1+r}^{x}}\right]
$$

where are weights that follow from (7),

$$
\begin{aligned}
& 2^{x}=\mu_{x}^{*}-\eta_{x}\left(1-\theta_{y}\right) \frac{\mu_{z}^{*}-\theta_{x}^{*}}{\mu_{x}-\theta_{x}} \\
& 0<\mu_{x}<1 \quad 0<\eta_{x}<1 \quad 0<\theta_{x}<1
\end{aligned}
$$

It is well-known that nonseparable preferences give rise to more variable intertemporal marginal rates of substitution (henceforth, IMRS) and asset prices (see for instance Hansen and Jagannathan (1991)). Habit forming utility might also account for the "persistence puzzle" mentioned above. In the continuoustime model of Sundaresan (1989), which fearures exogenous returns and endogenous consumption, habit formation induces very smooth and persistent consumption streams. In my model, the service technology transforms the exogenous endowment shocks into persistent service flows. This implies that endoument shocks have very prolonged effects on future IMRS. As a consequence, they will cause revisions in expectations of IMRS not only now but also in the future. Hence, the predictable pars of IMRS, interest rates (see below), might become very persistent as they are in the data.

I explore two commonly used specifications for the utility function which are special cases of the general preference framework in Eichenbaum and Hansen (1990). The first utility function is homothetic with intratemporal substitution between the "home" and "for eign" service flow equal to one.

$$
u\left(s_{1}{ }^{*}, s_{1}\right)=\frac{\left[\left(s_{1}^{*}\right)^{d}\left(s_{1}^{*}\right)^{1-\eta}\right]^{1} \neg}{1-\gamma}-1 \quad \delta \in(0,1) \quad \gamma \geq 0
$$

The parameter $\delta$ is a non-negative share parameter and $\gamma$ is a curvature parameter. The second specification is the so-called addilog utility function: 


$$
u\left(s_{1}^{x}, s_{1}^{n}\right)=\frac{\left(s_{1}^{x}\right)^{1-\gamma}}{1-\gamma}+\frac{\left(s_{1}^{2}\right)^{1-\gamma}}{1-\gamma} \quad \gamma \geq 0
$$

Although the combination of a multigood economy with nonseparable preferences complicates the interpretation of the utility parameters, I associate high values of the curvature parameter $\gamma$ with high risk aversion (low elasticity of intertemporal substitution) and vice versa. ${ }^{10}$

\section{Transaction cost function}

The transaction cost function is parameterized as a Cobb-Douglas function in the amount purchased $x(y)$ and real money balances $m(n)$.

$$
\Psi^{x}(x, m)=c_{1} x^{1} \cdot m^{1-x}, \quad \Psi^{y}(y, n)=c_{y} y^{b_{n}} n^{1-\xi} \quad c_{x}, c_{y}>0 \quad \xi_{2}, \xi,>1
$$

The function is increasing in $x$, decreasing in $m$ and homogeneous of degree 1 . The transaction cost technology embeds a CIA (cash-in-advance) constraim (when $\xi_{1} \rightarrow \infty, i=x, y$ ).

\section{Equilibrium}

The home household maximizes (6) over $\left\{x_{1}^{d}, y_{1}^{4}, M_{i+1}^{d}, N_{t+1}^{d}, z_{t+1}\right\}$ subject to the budget constraint in (5). An analogous problem is solved by the foreign representative resident. For markets to clear, the money demands in both countries must equal the supplies and the consurnption demands including the incurred transaction costs must exhaust the endowments. With the additional assumption of complete markets, the risk averse representative agents of both countries will share all risks. This leads to a tractable perfectly pooled equilibrium, introduced in Lucas (1982), in which no wealth re-distributions occur, agents consume constant fractions of the endowments and hold constant fractions of the market portfolio of assets."

\section{Endogenous variables}

In our frictionless world, the dollar price of an asset is the expected value of its nominal payoff discounted by the dollar IMRS. Let's denote the dollar IMRS hy mrs, of wealth at the time of the payoff, $\lambda_{t+1}$, to the marginal utility of wealth at time $t$ when the asset is 
purchased, $\lambda_{i}$ :

$$
\mathrm{mrs}_{\mathrm{ine}}=\boldsymbol{\beta} \frac{\lambda_{\mathrm{m}}}{\lambda_{1}}
$$

where $B$ is the discount factor. An analogous stochastic discount factor applies to assets that pay off in pounds. The $\lambda$ 's are the Lagrange multipliers associated with the sequence of budget constraints. The law of one price implies that the relative value of the marginal utility of pounds versus doll ars determines the dollar/pound exchange rate:

$$
s_{1} \lambda=\lambda_{i}^{*}
$$

where asterisks refer to pound variables. This indicates that the dollar will depreciate if its marginal utility decreases relative to the marginal utility of the pound. The home (foreign) interest rate $i_{\mathrm{s}}\left(\mathrm{i}_{i}\right.$ ) is the net return on a nominal bond yielding one dollar (pound) at time $t+n$. Hence,

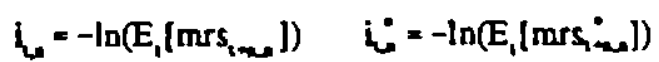

If market fundamentals move so as $w$ increase the expected marginal utility of the dollar, the dollar interest rate decreases, as it is the required return on an asset that pays off dollars when they are relatively valuable. As the forward premium is just the interest differential, the pound is at a discount if the value of the dollar's marginal utility is expected to increase more than that of the pound.

Once expressions for $\lambda_{1}$ and $\lambda_{1}^{*}$ are found, equation (14) yields the exchange rate and the domestic and foreign interest rates follow from (15). Using the formulas in equations (1) and (2), the forward premium and risk premium can be computed. Since $\lambda$ is the marginal utility of a dollar, it equals the total expected marginal utility of consumption divided by the transaction cost adjusted price of one unit of the home consumption good: 


$$
\lambda_{1}=\frac{\text { mux }}{\left(1+\frac{\partial \Psi_{1}^{2}(t)}{\partial x}\right) P_{t}^{x}}
$$

where $\Psi^{2}(t)$ is short-hand for $\boldsymbol{\Psi}^{2}\left(x_{1}^{d}, \mathbf{m}^{\prime}\right)$ evaluated at the equilibrium and mux was given in equation (8).

Define consumption velocity $V_{1}{ }^{2}$ as the endowment net of transaction costs times the price level divided by the money supply. ${ }^{n}$ In equilibrium, the first derivatives of the transaction cost function only depend on velocity:

$$
\frac{\partial \Psi^{2}(t)}{\partial x}=c_{z} \xi_{z}\left(V_{1}\right)^{t_{0}-1} \quad \frac{\partial \Psi^{2}(t)}{\partial m}=c_{z}\left(1-\xi_{z}\right)\left(V_{1}^{2}\right)^{t_{1}}
$$

Velocity can be solved for from the intertemporal Euler equation. To derive the intertemporal Euler equation heuristically, consider saving one dollar today. The marginal cost of this action equals the marginal utility of a dollar, $\lambda_{n}$. The marginal benefit of the dollar tomorrow not only includes the marginal utility of wealth tomorrow but also an additional retum as the dollar reduces transaction costs. Hence,

$$
\frac{\operatorname{mux}_{1}}{\left(1+\frac{\partial \Psi^{2}(t)}{\partial x}\right) P_{t}^{x}}=\beta E_{1}\left[\frac{\operatorname{mux}_{1+1}}{\left(1+\frac{\partial \Psi^{2}(t+1)}{\partial x}\right) P_{t+1}^{x}}\left(1-\frac{\partial \Psi^{2}(t+1)}{\partial m}\right)\right]
$$

where $m$ denotes real balances at time $t+1$. An analogous procedure yields $\lambda_{1}$.

\section{Speclfication of the law of mosion of the forcing processes}

In the simple economy described above, agents are subject to money supply and endowment shocks. Money and endowment growth rates are assumed to be observed weekly by the economic agents. Let $\mathrm{Mi}$ (N) be the home (foreign) money supply, and let $x_{1}(y)$ be the home (foreign) endowments. Furthermore, let $X_{1}=\left[\ln \left(M_{t}^{i} / M_{t-1}^{i}\right), \ln \left(x_{i}^{i} / x_{i-1}^{0}\right), \ln \left(N_{i} / N_{t-1}^{*}\right), \ln \left(y_{1}^{t} / y_{i-1}\right)\right]^{\prime}$. I assume the law of motion for $X_{1}$ to follow: 


$$
\begin{aligned}
& A(L) X_{1}=q_{0}+M(L) G_{7} \\
& \text { द| } \mathscr{S}_{\mathrm{I}-1}-\mathrm{N}(\mathrm{O}, \mathrm{H}) \\
& h_{1}^{\prime}-w_{1}+b_{1} h_{-1}^{i}+c_{1}\left(a_{-1}^{i}\right)^{2} \quad i=1,2,3,4 \\
& h_{1}{ }^{1}=\rho_{i}\left(h_{1}^{5}\right)^{3}\left(h_{1}^{5}\right)^{3} \quad i \neq j
\end{aligned}
$$

with $2_{0}$ a vector of constants, $A(L), M(L)$ polynomials in the lag-operator, $\epsilon_{2}$ a $4 x$ vector of innovations with conditional covariance matrix $H_{1}$ and $\mathscr{S}_{1}$ the information set at time $t$. The time variation in the second moments is parsimoniously modelled by a constant correlation GARCH $(1,1)$ model (see Bollerslev (1990)). This model has been very successful in capturing volatility clustering in financial series (see the survey in Bollerslev, Chou and Kroner (1992)).

The conditional mean specification is motivated, estimated and tested below. Time-varying second moments in the exogenous forcing processes are potentially important determinants of risk premiums in the forward market. Previous attempts at modelling the time-series behavior of exchange rates (Hodrick (1989)) or the risk premium (Canova and Marrinan (1993), Kaminsky and Peruga (1990)) by explicilly allowing for conditionally heteroskedastic forcing processes, have not been very successful. These models assume that the decision interval of the representative agents coincides with the monthly or quarterly interval at which the data were sampled. The failure to produce a variable enough risk premium is then due to the lack of sufficient time-variation in the second moments of consumption and money measures.

Time aggregation is an important issue here for two reasons. First of all, using highly aggregated data to estimate a conditional variance model might lead to poor estimates of the true heteroskedasticity in the data. A nice illustration is contained in Drost and Nijman (1993), who estimate GARCH models for various exchange rate series at different frequencies. They find that a monthly model implied by a daily or weekly model contains strong conditional heteroskedasticity although the homoskedasticity assumption could not be rejected by direct estimation of the monthly model. Second, the fact that time- 
averaged consumption data are used instead of spot consumption changes, might severely distort the measurement of consumption risk and the covariance between consumption and money. Both are important components of the risk premium in this model. ${ }^{13}$

\section{3, SOLVING AND CALIBRATING THE MODEL}

In this section, I first define the parameter and state vector for the model and briefly discuss bow the model is solved numerically. Since the model is too complex to allow estimation of all the parameters, I also discuss the choice of a set of benchmark parameter values. Finally, I describe the estimation technique for a sub-set of the parameters.

\section{Numerical solution of the madel}

The economic environment can be summarized by the parameters $\Phi$, the state vector $\theta_{1}$ and a set of Euler equations that the endogenous variables must satisfy. I partition the parameter space as $\Phi=[Z, 0]$, where $Z$ stacks the parameters of the law of motion of the forcing processes and $0=$ $\left[\beta, \gamma, q, c_{n}, c_{y}, \xi_{x}, \xi_{,}, \mu_{x}, \eta_{x}, \theta_{x}, \mu_{1}, \eta_{y}, \theta_{y}\right]$ with $\gamma$ denoting the curvanure parameter of the utility function and $q=\gamma$ for addilog utility, and $q=\delta$ for bomothetic utility. It will be useful to further partition the parameter space as follows. Let $Z_{1}$ denote the parameters governing the conditional mean equation and the unconditional variances and correlations of the four exogenous processes and let $Z_{2}$ denote the parameters governing the time variation in the conditional variances $\left[b_{i}, c_{i}\right](i=1,2,3,4)$. Hence, $Z=$ $\left[Z_{1}^{\prime}, Z_{2}^{\prime}\right]^{\prime}$. Furthermore, let $0=\left[D_{1}^{\prime}, Q_{2}^{\prime}\right]^{\prime}$, with $D_{1}=\left[\beta, \alpha, \gamma, c_{2}, c_{y}, \xi_{2}, \xi_{y}\right]$ and $D_{2}=\left[\mu_{x}, \eta_{x}, \theta_{x}, \mu_{y}, \eta_{y}, \theta_{y}\right]$.

Conditional on estimates for $\left[z, Q_{2}\right]$, the state vecior $\theta_{1}$ of the model can be determined. The growth rates for the exogenous state variables are denoted by, for example, $\mathrm{gm}_{\mathrm{H}}=\mathrm{M}_{\mathrm{l}}^{\mathrm{t}} / \mathrm{M}_{\mathrm{i}-1}^{*}$ (analogous definitions apply to $\left.g x_{1}, g m_{1} g y\right)$. The conditional variances $h_{1+1}$ are in the time $t$ information set and also part of the state vector. Because of the constant correlation GARCH model, they suffice to forecast furure conditional variances and co-variances. The stock of durables and the babit stock are introduced in 
stationary format by dividing by consumption levels as is done in Heaton (1993). Hence,

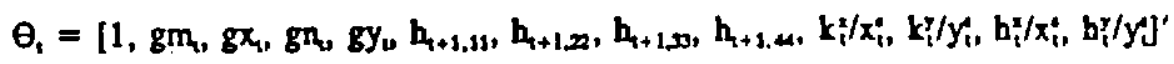

The crucial endogenous variables to be solved for are the velocities (equation (18)) and the marginal utilities (equation (8)). Once these variables are solved for, the other endogenous variables follow straightforwardly. The solution technique proceeds in two steps. First, a stationary representation of the relevant Euler equations is obtained where all variables depend only on the stationary state vector defined above. Then the endogenous variables are approximated by polynomials in the state variables and the Euler equations are numerically solved using the approach of Judd (1990). To evaluate expectations, 1 use Monte Carlo integration as in Heaton (1993) with 4,000 observations. A detailed description of the solution technique can be found in the appendix.

\section{Parameter Calibration}

For the homothetic utility specification I let $0_{1}=\left[.99^{(1 / 52)}, 1.1, .5, .09, .09,2.5,2.5\right]^{\prime}$, fot the addilog utility specification I let $Q_{1}=\left[.975^{(1 / 25)}, .2, .2, .09, .09,2.5,2.5\right]^{\prime}$. As described in the appendix, these parameters are calibrated to imply reasonable velocity and interest rate bebavior in the non-stochastic steady state of the model and to imply low transaction costs. Previous estimates of the curvature parameter in the utility function vary wildly but they are often quite low. ${ }^{14}$ Although the current specification of $\mathrm{O}_{2}$ imposes discipline on the simulations, I explore the implications of the model for a setting with more curvature in the utility function as well.

The $\Omega_{2}$-parameters are chosen as follows: $\eta_{x}=\eta_{y}=.75 \quad \theta_{x}=\theta_{y}=.95 \quad \mu_{x}=\mu_{y}=.76$. With $\mu_{x}=.76$, the half-life of durability is 2.5 weeks and three quarters of consumption vanishes within the month. This is consistent with the parameter estimates of Dunn and Singleton (1986) and Eichenbaum and Hansen (1990), since, as in these papers, consumption here is also measured as Nondurables and Services. The sum of the habit weights $\eta_{x}$ is based on the parameter estimates of Ferson and Constantinides (1991) and Heaton (1993), which vary between .60 and .95 . Estimates of simple nonseparability parameters typically 
typically favor durability when monthly data are used and favor habit persistence when quarterly or annual data are used. As Heaton (1993) stresses, these two findings can be plausibly reconciled by a parameter configuration in which durability dominates in the short run and babit effects in the long run. Or, in the notation of equation (9), a $>0$ for small $r$ and $a,<0$ for large $t$. This requires:

$$
\eta_{1}\left(1-\theta_{2}\right) \leq \mu_{1} \leq \theta_{2}+\eta_{2}\left(1-\theta_{2}\right)
$$

My choice of $\theta_{x}=.95$ implies positive a, within the quarter, and negative a, from the 9 th month onwards. As I do not know of any similar estimation exercises for the U.K., I fix these parameter values at the same levels as chosen for the U.S..

The parameters $Z$ are partially estimated using data on empirical proxies to the endowment and money supply shocks. I interpret the endowments as per capita consumption of nondurables and services in the U.S. (the home country) and the U.K. (the foreign country), respectively. The monetary shocks are assumed to be shocks to a broad money concept in these countries..$^{16}$ These data are sampled quarterly, which introduces a temporal aggregation problem into the estimation. In general, an attempt to identify parameters from a weekly model with quarterly data is plagued with the aliasing problem (see for instance Hansen and Sargent (1983), Nijman and Palm (1990)). There could be many models that yield observationally equivalent laws of motion for the quarterly data. Below I motivate a particular form for the general law of motion in equation (19) which bas the implication that $z_{1}$ is identifiable from quarterly data. The parameter vector $z_{1}$ can then be estimated by the General Method of Moments (Hansen (1982)).

Diebold (1986) proves that GARCH processes converge to unconditional normality under temporal aggregation, which might make it practically difficult to identify $Z_{2}$ from quarterly data." Therefore, I do not aftempt to estimate these parameters from the data. I further simplify interpretation of the results by assuming $b_{i}=b_{j}$ and $c_{i}=c_{p}, j, j=1, . .4$. Note that this does not imply that the conditional variances of the forcing processes are identical or that they are perfectly correlated, only that they move similarly 
over time, e.g. they have identical persistence. In the benchmark case, I put $b_{i}=.80, c_{i}=.13$, for all $i$. Taken as a univariate GARCH-model, this parameterization implies a kurtosis coefficient of .91 and a half-life of conditional variance shocks of 3 weeks. This is about half the kurtosis and persistence of conditional variance shocks implied by a univariate $\mathrm{GARCH}(1,1)$ model estimated from the weekly pound/\$ exchange rate data used in this paper. "The conditional heteroskedasticity assumed at the weekly level is also weak enough so that it disappears when the data are time-aggregated. ${ }^{19}$ In simulation exercises below, 1 explore various patterns of time variation in the second moments of the forcing processes and their implications for exchange rate behavior.

This completes the discussion of the parameter calibration. In what follows, I first further discuss the estimation of $z_{1}$. In the next section, I report all empirical results, including the estimation results for $Z_{1}$ and extensive simulation results.

\section{Estimaring $Z_{\text {, }}$}

I estimate the following simple parameterization of the general conditional mean specification in (19):

$$
\begin{aligned}
& A(L)=I-\left[\begin{array}{cccc}
a_{1.1} L & 0 & 0 & 0 \\
0 & 0 & 0 & 0 \\
0 & 0 & a_{1.1} L & 0 \\
0 & 0 & 0 & 0
\end{array}\right] \\
& M(L)=I
\end{aligned}
$$

In words, the money processes follow an $\operatorname{ARIMA}(1,1,0)$, whereas the consumption processes are martingales but the innovations of all four series are assumed to be correlated. Thile this model seems very simple, I will show that it generates sufficiently rich dynamics at the quarterly frequency to be consistent with the data.

To motivate this simple model, consider the time-series properties of the forcing processes in Table 2.0 The autocorrelations of the first differenced series, seported in Panel A, show that it would be hard to reject the hypothesis that the first autocorrelation of both consumption series is .25 and that the second 
autocorrelation is zero. The monetary aggregates are much more persistent than the consumption series. Panel B contains the results of a VAR on the 4 variables. Tests on the VAR order support a first order VAR. For each equation, I perform a Wald test for the joint significance of the coefficients on the variables other than the lagged left band side variable. Note the significant cross-effects, particularly in the U.K. equations. A test of the hypothesis that the innovation covariances are jointly zero also rejects. Diagnostic tests on the residuals of the first order VAR detect little evidence of significant serial correlation, heteroskedasticity or deviations from normality, with the exception of some remaining serial correlation in the U.S. consumption equation residuals.

I argue that these data patterns can be consistent with the simple law of motion specified in (19) because of temporal aggregation. The effects of time-averaging flow variables are well-known. In my model an additional complication arises because of the log-transformation. I choose to approximate logs of arithmetic averages with geometric averages as in Hall (1988) and Heaton (1993), i.e. I assume:

$$
\ln \left(\sum_{i=0}^{12} x_{i \rightarrow}^{*}\right)-\ln \left(\sum_{i=0}^{12} x_{i-13-7}^{0}\right) \approx \frac{1}{13} \sum_{i=0}^{12}\left[\ln \left(x_{i \rightarrow}^{*}\right)-\ln \left(x_{1-13-}^{*}\right)\right]
$$

A time-averaged random walk implies a first order autocorrelation of 25 (Working (1960)). For money, a stock variable, temporal aggregation will introduce an additional MA-component. As is shown in Bekaert (1992), the implied quarterly law of motion of the $\operatorname{ARIMA}(1,1,0)$ specification is $\operatorname{ARIMA}(1,1,1)$, which is potentially consistent with the data patterns.

The VAR tests show that the forcing variables are correlated which is accommodated through the assumption of correlated residuals in (19). The significant cross-effects in the conditional means might also be due to a time-aggregation effect. Bekaert (1992) gives a detailed description of the restrictions that the weekly model imposes on quarterly data and provides an identification proof for a model that embeds the parameterization in equation (19). Hence, the estimation of $Z_{1}$ is not subject to the aliasing critique. 
The model specified in (19) and (21) has 12 parameters: the two autocorrelation coefficients of the money processes and the distinct elements of the unconditional covariance matrix of the innovations, $\Sigma$. To guarantee positive semi-definiteness of $\Sigma_{e}$ I estimate its Cholesky-decomposition. I estimate the parameters by standard GMM. Let $\mathrm{X}_{4}$ contain the de-meaned quarterly observations on log-differences of money and consumption. Consider the function $f\left(X_{w}\right)$ that maps a subset of the data sample into a vector-valued stochastic process sucb that $(1 / T) \perp f\left(X_{w}\right)$ is a vector of sample moments at time $t$. Let $E\left[f\left(Z_{1}, X_{4}\right)\right]$ represent the corresponding vector of population moments. The parameters $Z_{1}$ are estimated with 16 orthogonality conditions, using the moments $E\left[f\left(X_{2,}, Z_{2}\right)\right]=\left[\operatorname{vech}\left(E\left(X_{2}, X_{2}\right)^{\prime}, E\left[X_{1}^{i} X_{i-1}^{i}\right], E\left[X_{4}^{j}\right.\right.\right.$. $X_{i-2,2]}^{\prime}$ for all $i$ and for $j=1,3$ with the indexing being the same as for $X_{n}$. As these moments are analytically known, construction of the orthogonality conditions is trivial. The estimation is done with a weighting matrix put equal to the inverse of a consistent estimate of the spectral density at frequency zero of the orthogonality conditions. The latter is estimated using a Bartlett kernel with an "optimal" bandwidth of 3 (Andrews (1991)). The estimation imposes 4 over-identifying testrictions which can be tested. To test the validity of the model, various other restrictions of the model will be tested using the methodology from Eichenbaum, Hansen and Singleton (1988).

\section{EMPIRICAL RESULTS}

Estimation of $Z_{1}$

Table 3 contains the estimation results for $z_{1}$. The estimation yields very persistent money supply rules. The parameters of the innovation covariance matrix are reasonably precisely estimated. The table reports the resulting standard deviations and correlations. The $x^{2}(4)$ test statistic of the over-identifying restrictions is 4.157 with a $\mathrm{p}$-value of .385 , indicating that there is no evidence against the restrictions.

The C-statistics, reported in the table, test some other restrictions implied by the model. The first set of restrictions tested is the implication of the model's weekly law of motion for consumption that the 
second autocovariance of quarterly consumption data ought to be zero. The second set of restrictions concerns the cross-moments of the quarterly variables. In general, the first order covariance of the quarterly measured data is non-zero but restricted by the weekly model. 1 test 6 cross-moment restrictions: the covariance between U.S. money and lagged U.K. money (and vice versa), between U.S. consumption and lagged U.K. consumption (and vice versa) and between U.S. (U.K.) consumption and lagged U.S. (U.K.) money. All these covariances were among the strongest in the VAR estimated on quarterly data. As the table shows, none of the tests performed rejects the restrictions imposed by the simple weekly model.

\section{Simulation results: Variability and persistence puzale}

Simulation results are reported for a CIA-model, the model with time-additive preferences, the model with durability only, the model with durability and habit persistence and finally for the complete model incorporating time-varying uncertainty in the fundamentals.

$$
\text { (1) A CU-Model }
$$

First, consider the case of addilog preferences in Table 4. Panel A contains simulations for the benchmark parameter values, whereas Panel $\mathrm{C}$ increases the curvature parameter for the utility function to 2. In a CIA-model with time-additive preferences, expressions for $\Delta q_{+1}$ and $\mathrm{fp}_{\mathrm{L}}$ in terms of the exogenous processes are given by:

$$
\begin{aligned}
& \Delta s_{1+2}=(\gamma-1)\left[\ln \frac{x_{1-1}^{*}}{x_{1}^{*}}-\ln \frac{y_{1+1}^{*}}{y_{1}^{*}}\right]+\ln \frac{M_{1+1}^{*}}{M_{1}^{*}}-\ln \frac{N_{1+1}^{*}}{N_{1}^{*}} \\
& f p_{s}=(\gamma-1)\left[u_{5}^{x}-u_{L_{0}^{\prime}}\right]+u_{5}^{M}-u_{5}^{N}+v
\end{aligned}
$$

where $u^{j}$ indicates the conditional mean of $\left.\ln G_{i+\alpha}^{i} / j^{j}\right), j=M, N, x, y$ and $v$ is a constant depending on the (co-) variances of the forcing processes. When $\gamma=1$ (log-utility), exchange rates only depend on money and are consequently highly persistent and not very variable. Likewise, forward premiums are very 
persistent and show considerable variance because future money supplies are highly predictable. When $\gamma$ differs from 1, exchange rates also depend on the supply shocks, which are uncorrelated (see above). Therefore, their variability increases and their persistence drops, which is apparent from both Panels $A$ and $\mathbf{C}$.

For the homothetic utility case, exchange rates only depend on the money processes and inherit their persistence. The CIA model, in general, seems to over-predict the persistence of exchange rates and under-predict its variability. The simple model implies realistic forward premium volatility and underpredicts its persistence at long horizons.

\section{(R) Introducing Transaction Costs}

Intuition on the effects of the different features of the model is best served by focussing on Panel $\mathrm{C}$. The transaction cost technology induces variable velocities. Variable velocity acts as an additional demand shock and both increases the variability of currency depreciation and dilutes the persistence that is injected by the highly autocorrelated money rules. However, it also implies less predictable IMRS, making their predictable parts, interest rates, less variable and less persistent.

\section{(3) Introducing Durabiliny}

Introducing durability potentially provides a remedy to this persistence puzzle. Suppose the agent expects high home endowment growth. Because she desires to smooth consumption, she attempts to consume part of the bumper crop now. As she is constrained by her present income, she attempts to sell bonds hence driving up interest rates which makes her willing to buy her share of the current endowment. With durability, a positive shock builds into the service flows and is likely to cause a revision of expectations in the next period as well, hence injecting more persistence in interest rates. The high depreciation rate $1-\mu_{2}$, and the lack of any correlation in the original endowment growth rates reduce the potential impact of durability. Also note that the IMRS are just about as variable here as they w'ere in the time-additive model, so that exchange rate variability is virtually unaffected. 


\section{(4) Introducing Habis Persistence}

The next column reports the results for the benchmark parameter configuration but with $Z_{2}$ still set equal to 0 . It offers the most satisfactory match with the data. The economic intuition behind the results is straightforward. With habit formation, consumers are more reluctant to diverge from smooth consumption streams. One could interpret the habit stock as a subsistence level of which it is very painful to deviate. This leads to more variable IMRS, exchange rates and forward premiums: when the fundamentals change or expectations get revised, bigger price movernents are needed to induce agents to hold the endowments. Although the model matches forward premium volatility, exchange rate variability is still somewhat too low. This specification also comes close to explaining the "persistence puzzle". The persistent service flows generated under this preference specification generate substantial persistence in endogenous interest rates, but the model still fails to deliver the persistence observed in forward premium data. On the other hand, the supply shocks cause a large enough forecast error in the IMRS to keep the persistence of exchange rates low. Strikingly, exchange rates show significant mean reversion at long horizons. ${ }^{21}$ This is also due to the long-run habit persistence built in. A positive home supply shock weakens the dollar by reducing its marginal utility. The endowment adds to the stock of durables and hence affects the marginal utility of the dollar next period as well. Or course, new shocks mitigate this effect and the positive persistence induced by this is not very high. The higher service flow today also adds to the habit stock tomorrow and the higher habit stock eventually increases the marginal utility of the dollar causing the negative correlations. As expected, negative correlations stan to dominate after two months.

When $\gamma$ is dropped to .2 in the benchmark case, the performance of all models is dismal. They all severely under-predict both the persistence and variability of exchange rate changes and forward premiums. Clearly, there has to be some curvature in the utility function for habit persistence to generate any significant effects. 
With homothetic preferences (Panel B), exchange rate changes and the forward premium become less variable and the forward premium somewhat less persistent. Agents have utility over a geometric average of the two service flows which implies smoother marginal utilities and IMRS.

\section{(S) Introducing Tme-varying Uncertainsy in the Fundamentals}

As all three panels show, the model under-predicts the variance of the risk premium by several orders of magnitude. Although habit persistence increases the standard deviation of the risk premium somewhat, the biggest effects are observed when time-varying uncertainty in the forcing processes is allowed for. Risk premium volatility is larger by a factor of over 2 (Panel A) to over 4 (Panel C), compared to the case without heteroskedasticity in the forcing processes. Time-varying uncertainty also increases the variability of both exchange rates and forward premiums. Still, even with $\gamma=2$, risk premium variability in the data is more than 50 times larger than in the model!

To sum up, the benchmark model performs better than previous models do but stills provides a very poor fit with the data. With risk aversion modestly higher than log-utility however, the model performs relatively well with respect to the persistence puzzle although it produces too much mean reversion in exchange rates and somewhat under-predicts the persistence of forward premiums. On the other hand, it fails drastically with respect to the variability premium puzzle, producing $\sigma\left(\Delta s_{+a D}\right)>\sigma\left(f_{p}\right)>$

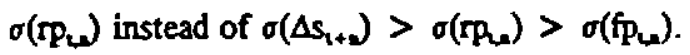

\section{Simulation results: Risk, uncertainsy and exchange rates}

The previous section has shown, that introducing conditional heterosked asticity in the model's market fundamentals substantially increases the variability of the risk premium. In this section, I want to address two additional questions. One is whether the model can produce fat tails and/or heteroskedasticity in weekly exchange rates and the forward premium and how much of these endogenous non-linearities are due to the heteroskedasticity in the forcing processes. Secondly, I want to further explore the effect on equilibrium exchange rate moments of different patterns of heteroskedasticity in the forcing processes. 
Table 5 shows the kurtosis coefficient of exchange rate changes and the differenced forward premium, and variance ratios for the squared series. The additional non-linearities introduced by variable velocity, durability and habit persistence belp to generate leptokurtosis and conditional beteroskedasticity in the endogenous variables. Nevertheless, the non-linearities induced in exchange rates are fairly weak whereas there is already quite some fat tails and serial dependence in the second moments of the differenced forward premium. In fact, for both benchmark specifications the model with habit persistence generates moments for the differenced forward premium that are almost within a two standard error band of the observed moments.

When time-varying uncertainty is introduced, all moments in all three specifications are within or very near a two standard error band of the observed moments. The moment that seems the hardest to match and is under-predicted is the leptokurtosis in exchange rate changes.

Next I examine the importance of both the persistence of conditional variance shocks to the fundamentals and the leptokurtic nature of the shocks. The former is governed by the coefficient on past variances in the GARCH specification whereas the latter is primarily governed by the coefficient on past residuals. In a first experiment, the hurtosis coefficient is fixed at its benchmark value and I vary $b_{i}$ so as to generate a balf-life of conditional variance shocks varying between 1 and 20 weeks. In a second experiment, I fix the persistence of conditional variance shocks (i.e. $b_{i}=.80$ ), but I adapt $c_{i}$ so as to generate kurtosis coefficients varying between 0.01 and 6.0. To conserve space, I do not report the full results but offer a brief discussion. First, at the benchmark parameters, varying the conditional variance properties has only minor effects on the variability of the endogenous variables. When $\gamma$ is set equal to 2 however, increasing the exogenous krtosis coefficient from 0.01 to 6.0 doubles the variability of the risk premium, although it only leads to modest increases in exchange rate and forward premium variability. Increasing the persistence of conditional variance shocks mainly increases the persistence of the forward premium without having significant effects on the variability of the endogenous variables. 
Second, not surprisingly, there are substantial effects on the non-linear behavior of the endogenous variables. Generally, a small degree of nonlinearities in the forcing process, coupled with the nonlinearities in the model, generates non-linear patterns in exchange rate changes and forward premiums that are consistent with what is observed in the data. For instance, there are different ways to generate a hurtosis coefficient of around 2.0 for exchange rate changes, which is less than 1 standard error below the sample moment of 3.0. In particular, the exogenous kurtosis coefficient can be increased to 4.0 or it can be kept at its benchmark value of .91 and the half life of conditional variance shocks can be increased from 3 weeks to about 10 weeks. As I will show below, the same effect can be accomplished through changing preference parameters as well.

Simulation results: Sensinivity analysis

To further explore the performance of the model, I vary respectively the curvature parameter, the habit weight parameter and the curvature parameter in the transaction cost technology, keeping the other parameters in the benchmark specifications constant. These three parameters are important determinants of the level of non-linearity in the model. Figure 1 shows the effect on 9 moments of changing the curvature parameter in the addilog specification. Similar graphs for the other experiments are available from the author on request. The moments involved are the standard deviation of exchange rate changes, the forward premium and the risk premium, the variance ratio (horizon 13) for exchange rate changes and the forward premium, the kurtosis coefficient for exchange rate changes and the forward premium and the variance ratio (horizon 13) for squared exchange rate changes and the squared differenced forward premium. The full horizontal line represents the sample value whereas the dotted horizontal lines are two standard error bands around the sample value. The parameter $\gamma$ is varied between 0 and 5.5 whereas the other parameters are fixed at their benchmark values.

In discussing the results of the sensitivity analysis, let us first focus on the volatility and persistence puzzles (Figures $1 \mathrm{a}$ and $1 \mathrm{~b}$ ). Increasing the curvature parameter, the sum of the babit weights or the 
curvature parameter in the transaction cost technology bas similar effects, albeit in differing degrees. The variability of IMRS and bence of exchange rates, the forward premium and the risk premium alike increases. Risk premium variability becomes only more realistic at a relatively bigh level of curvature in the utility function or bigh values for the babit weight parameter. For instance, for $\gamma>4$, risk premium variability is within the two standard error band. Exchange rate variability and forward premium volatility can be matched, but not simultareously. The effect of more habit persistence is minimal in the addilog case, as there is not enough curvature in the utility function. Increasing the babit weight also has ambiguous effects on the persistence puzle. Forward premium persistence goes up, but the model generates more mean reversion in exchange rates. Finally, the model does very well in generating realistic non-linear patterns in the forward premiums and exchange rate changes over a quite broad parameter range (see Figure 1c). Note bow increasing $\gamma$ also increases the endogenous leptohurtosis and beteroskedasticty in exchange rate changes. When $\gamma$ is larger than 5, leptokurtosis in exchange rates becomes unrealistically bigh. Generally, the effects of changing the transaction cost technology parameter are less propounced.

In changing other preference parameters, the most favorable effect occurs when $\theta$ is increased. This increases the long memory in the service flows. The effects on the addilog utility case with $\gamma=2$ of increasing $\theta$ to .97 can be seen in the EXP I-column in Table 4, Panel C. The variability of exchange rates is now within one standard error of the sample moment, whereas the persistence of the forward premium also increases. Although the variability of the forward premium is too high, it does increase percentage wise less than the variability of the risk premium does.

Lastly, it is possible to specify parameter configurations for which the standard deviation of the risk premium is within 2 standard errors of the sample standard deviation, without increasing the curvature parameter too much. As shown in the EXP III column of Table 4, Panel C, this comes at the cost of far too variable exchange rates and forward premiums. In the EXP II column, the same parameters are used 
but without heteroskedasticity. This once again shows the dramatic effect of adding time-varying uncertainty in the fundamentals to the model. Relative to EXP $\mathrm{I}$, time-varying uncertainty almost doubles the variability of forward premiums and exchange rate changes and leads to a more than tenfold increase in the volatility of the risk premium.

The failure of the model to generate sufficient risk premium volatility also surfaces in the correlations between future spot changes and the current forward premium. Not a single experiment in all my simulations yields negative correlations!

\section{CONCLUSIONS}

Standard frictionless monetary general equilibrium models fail to explain the relative variability and persistence of exchange rates, and the forward and risk premium. They also fail to capture their nonlinear behavior. In this paper, I maintained a frictionless rational expectations model but introduced a more realistic decision interval for the representative agents and more realistic preferences incorporating various forms of time nonseparabilities. The combination of time-varying uncertainty in the fundamentals and time aggregation was shown to be an important factor in explaining the risk premium puzze. Simulation results indicated that the risk premium can be made several orders of magnitude more variable than in previous models without implying very unreal istic endogenous moments for exchange rate changes and the forward premium. The non-linearities embedded in the model coupled with weak forms of timevarying uncertainty in the fundamentals endogenously generate substantial beteroskedasticity and leptokurtosis in exchange rates and the forward premium. Still, the model has the tendency to overpredict the variability of the forward premium and severely under-predict the variability of the risk premium. Although the persistence of forward premiums can be matched, it requires levels of risk aversion that imply slightly too variable forward premiums and exchange rates that are too meanreverting.

Several generalizations of the present model are potentially useful. Bekaert, Hodrick and Marshall 
(1994) for instance, explore the predictability of asset returns, including forward market returns, in a recursive preference framework with first-order risk aversion. Although first-order risk aversion also substantially increases the varjance of the risk premium relative to time-additive models, the model substantially under-predicts the variability of exchange rates, the forward premium and the risk premium.

The empirical results of Bekaert and Hodrick (1993) suggest another useful direction for further research. In an empirical re-examination of the unblasedness hypothesis, we find that unbiasedness bolds for the British pound during the $1975-1980$ period. In fact, the slope coefficient in a typical unbiasedness regression test is slightly larger than 1 for that sub-period. In the turbulent eighties, the rejection of unbiasedness is very severe. Interestingly, for the 1973-1976 period, i.e. before the system of floating exchange rates was formally implemented, we also find negative slope coefficients. It is possible that rational agents, faced with an array of policy signals, need time to recognize or "believe" changes in policy regimes. Such rational "learning" can lead to systematic forecast errors (see for instance Lewis (1989)) and partially explain the negative slope coefficients.

A third generalization is to break the complete markets set-up. In that case, the IMRS need not be equalized across countries. As agents can still self-insure through asset trading, asset prices might not differ very much from the complete market case. However, the perfect risk sharing assumed in this paper has several counterfactual implications. First of all, the extent of international portfolio diversification is actually very limited. Second, the set-up implicilly imposes Purchasing Power Parity (PPP), which is grossly violated in the data. In fact, when PPP-deviations exist, investors in different countries measure their real returns differently and generally desire to hold different portfolios (see Adler and Dumas (1983)). An additional channel to break PPP, is to explicitly model non-tradables. When utility is nonseparable in tradables and non-tradables, the IMRS's which are used to discount asset payoffs depend on non-tradables as well. Lastly, the large current account imbalances between major industrial countries indicate the usefulness of a general equilibrium model that allows wealth redistributions. I intend to explore a heterogeneous agent economy with non-tradable goods in the near future. 


\section{FOOTNOTES}

1. See the survey on conditional heteroskedasticity in asset prices by Bollerslev, Chou and Kroner (1992).

2. See for instance Bansal, Gallant, Hussey and Tauchen (1993), Bekaert (1994), and Canova and Marrinan (1993).

3. This frequency strikes a balance between the belief that periods of turbulence in asset prices at that frequency coincide with turbulent movements in market fundamentals such as money growth, productivity shocks and policy shifts, whereas at higher frequencies market micro structure effects might play a predominant role.

4. Bansal, Gallant, Hussey and Tauchen (1993) is a related, contemporaneous effort.

5. The analysis in Bekaert and Hodrick (1993) indicates that this is a barmless assumption.

6. For a recent assessment of these tests, see Bekaert and Hodrick (1993).

7. All the moments used in computing this coefficient are estimated in a joint General Method of Moments System (GMM).

8. This is consistent with the Vector Autoregressive Regression (VAR)-based estimates of Bekaert (1993).

9. The formulation implicitly assumes that there exist assets paying out the monetary transfers and endowments.

10. Constantinides (1990) for instance shows in a single good economy that habit persistence drives a wedge between the coefficient of relative risk aversion and the inverse of the elasticity of intertemporal substitution.

11. Relaxing this assumption can only occur at considerable computational cost and would make it impossible to solve the model with time nonseparable preferences and conditional volatility shocks. Preliminary results of general equilibrium analysis with beterogeneous agents and incomplete markets, suggest that agents manage to smooth consumption very well with only a limited number of available assets (see e.g. Lucas (1991) and Marcet and Singleton (1990)). Consequently, asset prices do not differ very much from the complete markets case.

12. The empirical proxy for the endowments will be taken to be net of transaction costs.

13. A lognormal example that links the risk premium to the second moments of the forcing processes is worked out in an appendix available from the author.

14. See for instance Bansal, Gallant, Hussey and Tauchen (1993) and Canova and Marrinan (1993) for parameter estimates lower than 1 in an international framework.

15. Whereas they did not allow for lags beyond two months, my specification implies that less than $10 \%$ of the stock remains after 2 months.

16. See the Data Appendix for more details. 
17. Results on the time-aggregation of GARCH-processes are scarce. Drost and Nijman (1993) restrict themselves to univariate models and show that strong forms of GARCH are not closed under temporal aggregation.

18. The parameter on the past conditional variance equals .882 , the coefficient on the past squared innovation .094, implying a half-life of conditional variance shocks of 5.54 and a kurtosis coefficient of 1.82.

19. For a small Monte Carlo experiment demonstrating this, see Bekaert (1992).

20. The log-difference specification of (19) is justified by the unit root and cointegration tests reported in Bekaert (1992).

21. Huizinga (1987) actually finds evidence for mean reversion in real exchange rates. 


\section{DATA APPENDIX}

The exchange rate data are daily data from Citicorp Data Services. Bob Korajzyck supplied DRI Eurocurrency interest rates running until mid 1988 which were obtained at INSEAD. All rates are sampled each Friday and averages of bid and ask rates. When Friday was a holiday, the Thursday rate was picked.

Quarterly consumption on nondurables and services is taken from the OECD Quarterly National Accounts. The U.K. semi-durables category is included as it is comprised of consumption items that are included in the nondurables category for the United States. The series are seasonally adjusted and in 1982 dollars, resp. 1985 pounds.

Money is measured as end-of-the-quarter M2 money stocks. For the U.S., M2 is taken from Citibase. Due to the introduction of MMDAs and super NOW accounts, there is an outlier in the U.S. data in the first quarter of 1983 . The money growth rate for that quarter is replaced with a weighted average of past and future growth rates, incorporating 18 quarters of data. Published monetary aggregates in the U.K. cannot be used as there were several definitional changes that make it virtually impossible to deduce a consistently defined series over the whole sample. Therefore, I obtained data on the concept M4 directly from the Bank of England. It is a broad aggregate comparable to M2 in the U.S. except that it also includes deposits (including Certificates of deposits) with building societies. In November 1981, a big financial institution (the trustes savings bank) turned into a bank, increasing the money supply by 7.5\% overnight (see Bank of England Quarterly Bulletin, Dec. 1981). This outlier was corrected for in a similar fashion as the U.S. outlier. The money series are also seasonally adjusted. Both the money and real consumption data were divided by total population (series $99 \mathrm{z}$ in the International Financial Statistics data set) to arrive at per capita data. The population data are mid-year estimates which are linearly interpolated to obtain quarterly data. 


\section{APPENDIX 1: THE CALIBRATION OF $\mathbf{Q}_{\mathbf{1}}$}

In the non-stochastic steady state of the model, the expressions for velocity and interest rates only depend on the parameters in $\emptyset_{1}$. In the case of addilog utility, steady state home consumption velocity is given by

$$
\bar{v} x=\left(c_{x}\left(5^{x}-1\right)\right)^{\frac{1}{k}}\left[\frac{\overline{g m} \overline{g x}+-1}{\beta}-1\right]^{\frac{1}{1}}
$$

with upper bars denoting steady state values. Likewise, the four week steady state interest rate is defined by

$$
(1+\overline{1})^{-1}=\beta \frac{\overline{g x}(12-\gamma)}{\overline{g m}}
$$

The expressions for steady state interest rates and velocity for the homothetic utility case are

$$
\begin{aligned}
& \bar{v}^{n}=\left[c_{x}\left(\xi^{x}-1\right)\right]^{\frac{1}{k^{n}}}\left[\frac{\overline{g r a}(\overline{g x} \cdot \overline{g y}(1-d)) r-1}{b}-1\right]^{\frac{1}{b}} \\
& (1+\bar{i})^{-1}=\beta+\frac{\left(\overline{g x} \overline{g y}^{(1-3)}\right)+(1-7)}{\overline{g x}}
\end{aligned}
$$

Total transaction costs as a proportion of total consumption, $\mathrm{TC}_{\mathbf{x}}$ in steady state are given by

$$
T C_{2}=c_{x}\left(\vec{v}^{2}\right)^{r+1}
$$

The expressions for the foreign good are similar.

To obtain empirical estimates of the steady state values, I obtain monthly interest rate means from the interest rate data used in the paper, and quarterly velocity means from the $O E C D$ data on consumption and consumption deflators and the money supply data described in the Data Appendix.

To link quarterly $\left(V_{S}\right)$ and weekly $\left(V_{*}\right)$ velocity, I assume:

$$
\bar{v}_{q}^{x}=\bar{v}_{i} \times \frac{1-\overline{g^{13}}}{1-\overline{g n}^{13}}
$$


An analogous expression bolds for foreign consumption velocity.

1 consider the following parameter range:

$B \in\{.95, .955, .96, \ldots, 1.0\}$

$\gamma \in\{0, .1, .2, .3, \ldots, 2.9,3.0,3.25,3.50, \ldots, 10.25\}$

$c_{x}=c_{\gamma} \in(.0001, .001, .002, \ldots, .01, .02, \ldots, .1)$

$\xi_{\mathrm{z}}=\xi_{\mathrm{y}} \in\{1.25, \ldots, 2.0,2.5,3.0,4.0,5.0\}$

To find a "reasonable" parameter configuration for $Q_{1}$, the following procedure is performed:

(1) Compute mean growth rates of bome and foreign consumption and money from the simulated observations according to the law of motion specified in equation (19) in the text, i.e. $E_{1}$ is set equal to its estimated values but $z_{2}$ is set equal to 0 .

(2) For each parameter configuration, compute the steady states for velocity, the monthly interest rates and transaction costs $\mathrm{TC}_{\mathbf{n}}$ and $\mathrm{TC}$, using equations (1)-(5).

(3) Discard parameter configurations which yield $\mathrm{TC}_{\mathbf{3}}$ or $\mathrm{TC}_{\mathbf{y}}>.01$ and $<.0001$.

(4) Discard parameter configurations which yield too high or too low velocity. The lower bound is computed as the weekly equivalent from the quarterly mean, computed with the data used in the paper. As I used a broad monetary aggregate, I consider these means to over-estimate the mean of velocity consistent with the transaction cost technology modelled in the paper. I also compute an "adjusted * mean by multiplying all the velocities with the ratio of consumption to GNP as in Marshall (1992). I use this quarterly mean as the upper bound for weekly velocities. Hence, the velocity mean requirements are weak.

(5) Of the remaining parameter configurations, these parameters are chosen that come closest to matching the interest rate means. For both utility functions, the resulting parameter configurations are nearly within a 3 standard error band of the data means. 


\section{APPENDIX 2: SOLVING THE MODEL}

As indicated in the text, the marginal utilities mux, muy, and the consumption velocities $V_{10}, V_{1}$ must be determined. The expression for mux, follows from equations (8) and $(9)$ in the text. It can be rewritten as:

$$
\begin{aligned}
& \operatorname{mux} x_{1}=w_{1} \operatorname{dmux} x_{1}+w_{2} h m u x_{1} \\
& w_{1}=1-\frac{\eta_{2}\left(1-\theta_{2}\right)}{\mu_{x}-\theta_{2}} \quad w_{2}=\frac{\eta_{1}\left(1-\theta_{1}\right)}{\mu_{2}-\theta_{x}} \\
& \operatorname{dmux} x_{1}=E_{1}\left[\sum_{=0}^{\infty} \beta^{r} \mu_{2}^{*} \frac{\partial u\left(s_{1-n}^{x}, s_{1-\infty}^{y}\right)}{\partial s_{1-\infty}^{\prime}}\right] \\
& h m u x_{1}=E_{1}\left[\sum_{=0}^{\infty} \beta^{r} \theta_{x}^{r} \frac{\partial u\left(s_{1+\infty}^{2}, s_{1+\infty}^{y}\right)}{\partial s_{1+\infty}^{\prime}}\right]
\end{aligned}
$$

A remaining problem is that, consistent with what is observed, the endowments and money supplies are assumed to grow over time. Therefore, I solve for a stationary equilibrium, in which stationary endogenous variables such as exchange rate changes, inflation and velocity depend only on stationary state variables, including growth rates of money supplies and endowments. To induce stationarity in the stocks of consumption goods and the habit stocks, I divide by the level of consumption. This normalization is used by Heaton (1993) and leads to a natural stationary representation of the state vector. Define a scaled marginal utility as:

$$
\operatorname{smux}_{1}=\frac{\operatorname{mux}}{\frac{\partial u\left(x_{1}^{d}, y_{1}^{d}\right)}{\partial x_{1}^{d}}}
$$

where the denominator is the particular period-utility function evaluated at present equilibrium consumption purchases. Define sdmux, analogously by replacing mux, in (8) by dmux. Then sdmux, solves the following difference equation:

An analogous equation applies to hmux, Once market clearing is imposed, the marginal utility ratios in (9) will be direct functions of the state vector and the difference equation can be solved for sdmux. Note that: $s$ mux $=w_{1}$ sdmux $+w_{2}$ shmux. With the solution for smux, the Euler equation determining 


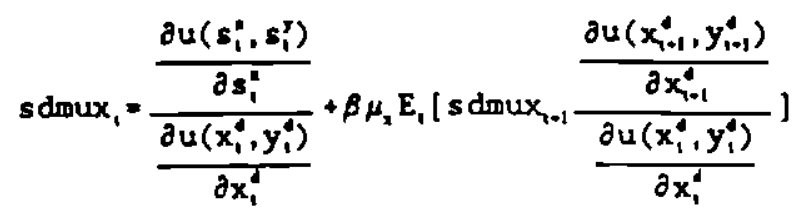

velocity can be re-written in stationary format:

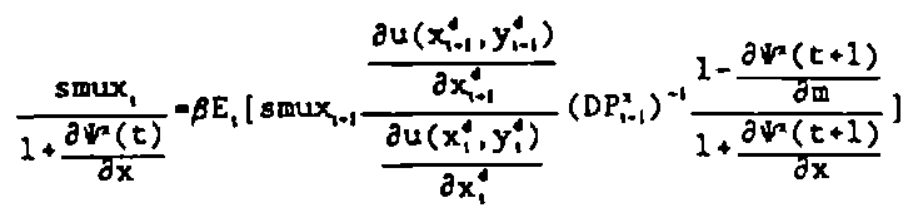

As the right hand side depends on state variables at time $t$, equation $(10)$ describes the solution for $\partial \Psi^{x} / \partial x$ and hence for velocity.

Let $\theta_{1} \in \mathrm{R}^{\mathrm{K}}$ be the vector of stationary state variables which completely spans the information set and $\varphi_{1}=\left[V_{1}^{x}, V_{s}^{3}\right.$, smux, smuy $]$, the set of endogenous variables to be solved for. The other endogenous variables are trivial functions of $\varphi_{1}$. As the model is dichotomous in $\varphi_{1}^{x}=\left[V_{1,}^{x}\right.$, mux $]$ and $\varphi_{1}^{v}=\left[V_{1}^{y}\right.$, smuy., I can restrict the discussion to the solution method for $\varphi_{1}^{2}$. The two basic. Euler equations that must be solved in this model are (9) and (10). They are of the form:

$$
\Lambda\left(\varphi_{1}, \theta_{1}\right)=E_{1}\left[\Gamma\left(\varphi_{1-1}, \theta_{1-1}\right)\right]
$$

where $\Lambda(.,$.$) and \Gamma(.,$.$) are known functions. As \varphi_{1}$ is a continuous function mapping $R^{k}$, the space of the state variables $\theta_{v}$ into $R_{1}$ it can be approximated arbitrarily well by polynomials. The polynomial coefficients are found by minimizing the approximation error over some norm. The technique I use follows Heaton (1993) in employing Monte Carlo integration to evaluate expectations. Marcet and Marshall (1993) actually formally prove that, when the sample size and the polynomial order, approach infinity, the numerical equilibrium solution converges to the Rational Expectations Equilibrium.

More specifically, I first solve for the scaled marginal utilities. Let $\rho_{2}(\theta)$ be a vector of polynomial elements in $\theta_{1}$ of degree $\leq \mathrm{n}$. Denote $\left.f_{2}\left(\theta_{1} ; q_{2}\right)=\left[\Theta_{2}\left(\ln \left(\theta_{j}\right)\right)^{\prime} q_{l}\right]\right)$, where $q_{2}$ indicates the polynomial 
coefficients. Let sdmux $=f_{0}\left(\theta_{i} ; q_{e}\right)$. Substitute this in the difference equation (8) to find the approximation error $u\left(\theta_{i} ; q_{2}\right)$ :

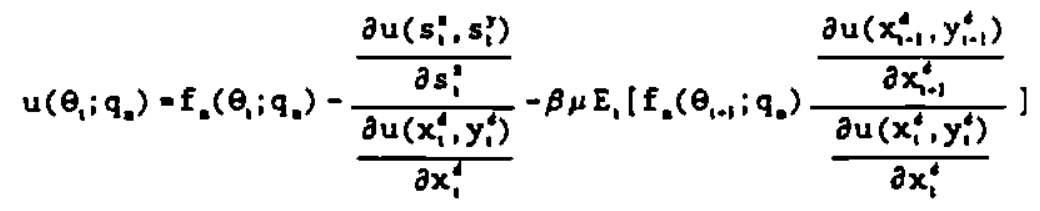

The parameters $q$ are chosen such as to make $u\left(\theta_{\mathrm{u}} q_{2}\right)$ orthogonal to the polynomial elements $p\left(\theta_{1}, q_{v}\right)^{\prime}$ or:

$$
E\left[u\left(\theta_{1} ; q_{2}\right) p_{n}\left(\theta_{1}\right)\right]=0
$$

By the law of iterated expectations, this can be rewritten as:

$$
E\left[\left(f_{2}\left(\theta_{1} ; q_{2}\right)-\frac{\frac{\partial u\left(s_{1}^{2}, s_{1}^{p}\right)}{\partial s_{1}^{x}}}{\frac{\partial u\left(x_{1}^{d}, y_{1}^{d}\right)}{\partial x_{1}^{d}}}-\beta \mu f_{0}\left(\theta_{t+1} ; q_{2}\right) \frac{\frac{\partial u\left(x_{1+1}^{d}, y_{1+1}^{d}\right)}{\partial x_{1+1}^{d}}}{\frac{\partial u\left(x_{1}^{d}, y_{1}^{d}\right)}{\partial x_{1}^{d}}} \mid p_{n}\left(\theta_{1}\right)\right]=0\right.
$$

The expectation can be taken by Monte Carlo integration, i.e. by drawing a long time series for $\theta_{1}$ and taking sample averages of the expression in equation (14). The coefficients qo then follow from solving a system of non-linear equations. The difference equation for shmux is solved analogously and smux, is obiained as in equation (7).

To solve for velocity, approximate $V_{t}^{x}$ by polynomials and substitute the approximate velocity function into equation (10). In this case the polynomials will be exponentiated to guarantee positive velocities. The marginal utility smux, is replaced by its approximation previously solved for. This will give rise to

'This is the Galerkin method, one of the Minimum Weighted Residuals (MWR) methods, described by Judd (1990). 
an approximation error that is projected onto the polynomial elements in order to solve for the polynomial coefficients. $^{2}$

2 It is stralghtforward to compute analytical derivatives for the varlous non-linear systems so that solutions are obtained relatively fast even for large state spaces. 


\section{REFERENCES}

Abel, A. B., 1988, "Stock Prices under Time-varying Dividend Risk: An Exact Solution in an Infinite Horizon General Equilibrium Model," Joumal of Monetary Economics 22, 375-394.

Adler, M. and B. Dumas, 1983, "International Portfolio Choice and Corporation Finance," The Journal of Finance 38, 925-984.

Andrews, D. K., 1991, "Heteroskedasticity and Autocorrelation Consistent Covariance Matrix Estimation," Econometrica 59, 817-858.

Backus, D., A. Gregory and C. Telmer, 1993, "Accounting for Forward Rates in Markets for Foreign Currency", Loumal of Finance 5, 1887-1908.

Baillie, R. and T. Bollerslev, 1989, "The Message in Daily Exchange Rates: A Conditional Variance Tale," Lournal of Business and Economic Statistics 7, 297-305.

Bansal, R., A. R. Gallant, R. Hussey and G. Taucben, 1993, "Nonparametric Structural Estimation of Models for High-Frequency. Currency Market Datz," Manuscript, Duke University.

Bekaert, G., 1992, "Empirical Analyses of Foreign Exchange Markets: General Equilibrium Perspectives," Ph. D. Dissertation, Northwestern University.

1993. The Time-variation of Expected Returns and Volatility in Foreign Exchange Markets," Manuscript, Stanford University. G., 1994, "Exchange Rate Volatility and Deviations from Unbiasedness in a Cash-inAdvance Model," Journal of Intermational Economis 36, 29-52. 1993, "On Biases in the Measurement of Foreign Exchange Risk Premiums," loumal of Intermational Money and Finance April 1993.

Bekaert, G., R. Hodrick and D. Marshall, 1994, "The Implications of First-Order Risk Aversion for Asset Market Risk Premiums," Manuscript.

Bera, A. K. and C. M. Jarque, 1982, 'Model Specification Tests: A Simultaneous Approach, Journal of Econometrics 20, 59-82.

Bollerslev, T., 1990, "Modeling the Coherence in Short Run Nominal Exchange Rates: A Multivariate Generalized ARCH Model," Review of Economics and Statistics 72, 498-505.

Bollerslev, T., R. Y. Chou and K. F. Kroner, 1992, "ARCH Modeling in Finance: A Review of the Theory and Empirical Evidence," Joumal of Econometrics 52, 5-60.

Canova, F. and J. Marrinan, 1993, "Profits, Risk and Uncertainty in Foreign Exchange Markets," Loumal of Monetacy Economics 32, 259-286. 
Constantinides, G. M., 1990, "Habit Formation: A Resolution of the Equity Premium Puzzle, Lournal of Political Economy 98, 519-543.

Cumby, R. E. and J. Huizinga, 1992, "Testing the Autocorrelation Structure of Disturbances in Ordinary Least Squares and Instrumental Variables Regressions," Econometrica 60, 185-196.

Diebold, F. X., 1986, "Temporal Aggregation of ARCH Models and the Distribution of Asset Returns," mimeo.

Drost, F. C. and T. E. Nijman, 1993, "Temporal Aggregation of GARCH Processes," forthcoming Econometrica 61, 909-928.

Dunn, K. B. and K. J. Singleton, 1986, "Modelling the Term Structure of Interest Rates under Nonseparable Utility and Durability of Goods" Lournal of Financial Economics 17, 27-55.

Eichenbaum, M.S. and L.P. Hansen, 1990, Estimating Models with Intertemporal Substitution Using Aggregate Time Series Data, Joumal of Business and Economic Statistics 8, 53-69.

and K. J. Singleton, 1988, "A Time Series Analysis of a Representative

Agent Model of Consumption and Leisure Choice under Uncertainty," Ouarterly Joumal of

Economics, 51-78.

Engle, R., 1982, Autoregressive Conditional Heteroskedasticity with Estimates of the Variance of U.K. Inflation, Econometrica 50, 987-1008.

Ferson, W. and G. M. Constantinides, 1991, "Habit Persistence and Durability in Aggregate Consumption: Empirical Tests", Joumal of Financial Economics 29, 199-240.

Hall, R. E., 1988, "Intertemporal substitution in consumption," Journal of Political Economy 96, 339-357.

Hansen, L. P., 1982, "Large Sample Properties of Generalized Method of Moments Estimators," Econometrica 50, 1029-1054.

and R. Jagannathan, 1991, "Implications of Security Market Data for Models of Dynamic Economies," Journal of Political Economy 99, 225-262.

and T.J. Sargent, 1983, The Dimensionality of the Aliasing Problem in Models with Rational Spectral Densities," Econometrica 51, 377-88.

Heaton, J., 1993. "An Empirical Investigation of Asset Pricing with Temporally Dependent Preference Specifications," Manuscript, M.I.T.

Hodrick, R. J., 1989, "Risk, Uncertainty and Exchange rates," Joumal of Monetary Economics $23,433-460$.

Huizinga, J., 1987, "An Empirical Investigation of the Long-run Behavior of Real Exchange Rates, " Cameqie-Rochester Conference Series on Public Policy 27. 
Judd, K. L., 1990, "Minimum Weighted Residuals Methods for Solving Dynamic Economic Models," Manuscript, Stanford University.

Kaminsky, G. and R. Peruga, 1990, "Can a Time-Varying Risk Premium Explain Excess Returns in the Forward Market for Foreign Exchange?" Joumal of Intemational Economics 28, 47-70.

Lewis, K., 1989, "Changing Beliefs and Systematic Rational Forecast Errors with Evidence from Foreign Exchange", American Economic Review 79, 621-636.

Lucas, D., 1991, "Asset Pricing with Undiversifiable Income Risk and Short Sales Constraints:

Deepening the Equity Premium Puzzle," Manuscript, Northwestern University.

Lucas, R. E., 1978, "Asset Prices in an Exchange Economy", Econometrica, 46, 1429-1445.

Lucas, R. E., 1982, "Interest Rates and Currency Prices in a Two-Country Worid," Lournal of Monetary Economics 10, 335-360.

Marcet, A. and D. Marshall, 1993, "Convergence of Approximate Model Solutions to rational Expectations Equilibria Using the Method of Parameterized Expectations," Manuscript, Northwestern University.

and K. J. Singleton, 1990, "Optimal Consumption-Savings Decisions and Equilibrium Asset Prices with Heterogeneous Agents Subject to Portfolio Constraints, Manuscript, Stanford University.

Marshall, D., 1992, "Inflation and Asset Returns in a Monetary Economy," Journal of Finance 47, 1315-1342.

Newey, W. and K. West, 1987, 'A Simple, Positive Semi-definite, Heteroskedasticity and Autocorrelation Consistent Covariance Matrix," Econometrica 55, 703-708.

Nijman, T. E. and F. C. Palm, 1990, "Parameter Identification in ARMA Processes in the Presence of Regular but incomplete Sampling," Joumal of Time Series Analysis 11, 239-248.

Poterba, J. A. and L. H. Summers, "The Persistence of Volatility and Stock Market Fluctuations," American Economic Review 76, 1142-1151.

Sundaresan, S.M., 1989, "Intertemporally Dependent Preferences and the Volatility of Consumption and Wealth," Review of Financial Studies 2,73-89

Svensson, L., 1985, "Currency Prices, Terms of Trade and Interest Rates: A General Equilibrium Asset Pricing Cash-in-advance Approach" Journal of International Economics, 17-41.

Working, H., 1960, "Note on the Correlation of First Differences of Averages in a Random Chain," Econometrica 28, 916-918. 
Table 1

Time series properties of exchange rates, the forward premlum and term spreads

The sample period is January 1975 to December 1990 . Observations are sampled weekly on $\Delta s$, the weekly logarithmic exchange rate change, $f_{p}$, measured as the difference between the U.S. one month interest rale and the UK one month irterest rale. All inlerest rates are annualized, ie. they are multiplied by 1200 . Weekly currency depreciation is also multiplied with 1200. The symbol $\sigma$ abways denotes the standard deviation, ac denotes the nth autocorrelation and $v_{1}$ the variance ratio including $i$ aulocorrelations, estimaled as in Equation (4) in the paper. In the third row, the normalized kurtosis coefficient ku is computed for (de-meaned) currency depreciation and for the differenced forward premium. The standard errors are derived by GMM. The mean, standard deviation, kurtosis coefijcient and the moments reported in Pancl B are estimated jointly using 13 Newey-West (1987) lags in calculating the variance matrix. The standard errors for the variance ratios follow from the joint estimation of $\mathbf{5 2}$ autocorrelations and their variance matrix using 51 Newey. West lags. The crosscorrelations in Panel B are between the forward premium and future exehange rale changes and between the differenced forward premium and squared demeaned depreciation respectively.

Panel A: Unlvarlate properties

\begin{tabular}{|c|c|c|c|c|}
\hline & $\Delta \mathrm{s}$ & $\mathrm{fP}_{\mathrm{A}}$ & $(\Delta s)^{3}$ & $\left(\Delta \mathrm{f}_{\mathrm{LA}}\right)^{3}$ \\
\hline mean & $\begin{array}{c}-.319 \\
(.702)\end{array}$ & $\begin{array}{l}-2637 \\
(.426)\end{array}$ & & \\
\hline$\sigma$ & $\begin{array}{r}17.668 \\
(1.069)\end{array}$ & $\begin{array}{l}3.481 \\
(343)\end{array}$ & & \\
\hline $\mathbf{k u}$ & $\begin{array}{c}3.000 \\
(1.290)\end{array}$ & & & $\begin{array}{c}8.635 \\
(2495)\end{array}$ \\
\hline$a c_{1}$ & $\begin{array}{c}.025 \\
(.037)\end{array}$ & $\begin{array}{c}972 \\
(.007)\end{array}$ & $\begin{array}{c}.171 \\
(.073)\end{array}$ & $\begin{array}{c}.145 \\
(.057)\end{array}$ \\
\hline$a c_{2}$ & $\begin{array}{c}.006 \\
(.054)\end{array}$ & $\begin{array}{c}949 \\
(.012)\end{array}$ & $\begin{array}{c}.160 \\
(.055)\end{array}$ & $\frac{208}{(.083)}$ \\
\hline acs & $\begin{array}{c}.044 \\
(.034)\end{array}$ & $\begin{array}{c}925 \\
(.019)\end{array}$ & $\begin{array}{c}.194 \\
(.047)\end{array}$ & $\begin{array}{c}.199 \\
(.031)\end{array}$ \\
\hline$a c_{y}$ & $\begin{array}{l}-.033 \\
(.036)\end{array}$ & $\begin{array}{c}873 \\
(.031)\end{array}$ & $\begin{array}{c}.197 \\
(.104)\end{array}$ & $\frac{208}{(.070)}$ \\
\hline$a c_{13}$ & $\begin{array}{l}-.008 \\
(.039)\end{array}$ & $\begin{array}{c}678 \\
(.075)\end{array}$ & $\begin{array}{l}. .005 \\
(.021)\end{array}$ & $\begin{array}{c}.072 \\
(.022)\end{array}$ \\
\hline$v_{4}$ & $\begin{array}{l}1.110 \\
(.070)\end{array}$ & $\begin{array}{l}4.794 \\
(.049)\end{array}$ & $\begin{array}{l}1.663 \\
(229)\end{array}$ & $\begin{array}{l}1.702 \\
(210)\end{array}$ \\
\hline$v_{13}$ & $\begin{array}{l}1.304 \\
(.133)\end{array}$ & $\begin{array}{l}12350 \\
(390)\end{array}$ & $\begin{array}{l}2419 \\
(.427)\end{array}$ & $\begin{array}{l}2718 \\
(.413)\end{array}$ \\
\hline$v_{\mathbf{x}}$ & $\begin{array}{l}1.460 \\
(.195)\end{array}$ & $\begin{array}{l}21.097 \\
(1295)\end{array}$ & $\begin{array}{l}3.177 \\
(.495)\end{array}$ & $\begin{array}{l}3.746 \\
(.634)\end{array}$ \\
\hline$v_{52}$ & $\begin{array}{l}1.725 \\
(.314)\end{array}$ & $\begin{array}{l}32798 \\
(3.667)\end{array}$ & $\begin{array}{l}4.101 \\
(.717)\end{array}$ & $\begin{array}{c}5.957 \\
(1.174)\end{array}$ \\
\hline
\end{tabular}


Panel B: Cross cortrlatoos

\begin{tabular}{|c|c|c|c|c|}
\hline & $\Delta_{\mathrm{q}+1} /\left(\Delta_{\mathrm{q}+1}\right)^{1}$ & $\Delta_{\mathrm{q}+2} /\left(\Delta_{\mathrm{q}, 2}\right)^{2}$ & $\Delta_{\left.\mathrm{q}_{+}\right)} /\left(\Delta_{\mathrm{q}+1}\right)^{2}$ & $\Delta_{\mathrm{s}, \mathrm{A}} /\left(\Delta_{\mathrm{s}, .0}\right)^{2}$ \\
\hline$f_{P_{4}}$ & $\begin{array}{c}. .097 \\
(.038)\end{array}$ & $\begin{array}{r}. .104 \\
(.038)\end{array}$ & $\begin{array}{r}.104 \\
(.039)\end{array}$ & $\begin{array}{r}. .112 \\
(.037)\end{array}$ \\
\hline$\left(\Delta \mathrm{fP}_{\mathrm{B}}\right)^{2}$ & $\begin{array}{c}.051 \\
(.068)\end{array}$ & $\begin{array}{r}.036 \\
.019) \\
\end{array}$ & $\begin{array}{c}.020 \\
(041)\end{array}$ & $\begin{array}{l}-.020 \\
(.024)\end{array}$ \\
\hline
\end{tabular}


Table 2

Time serles propertles of the forclng processes

The standard errors of the autocorrelations are computed by GMM, using the heteroskedasticity and autocorrelation consistent covariance estimator described in Andrews (1991) with a Bartlett kernel and optimal bandwidth of 2 . The appropriate lag length for the VAR minimizes the Akaike or Schwarz criterion in $P$ anel B. Parameter estimates are obtained by OLS and reported in Panel C with beteroskedasticity consistent standard

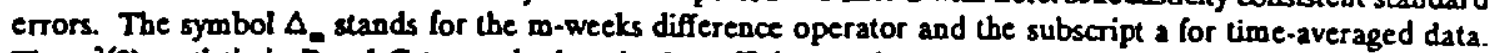
The $x^{2}(3)$ statistic in Panel $C$ tests whether the 3 coefficienis other than the one on the lagged left band side variable are jointly equal to zero. A test statistic on the joint significance of the 6 innovation covariances is also reported. The test statistic is derived from the joint distribution of the VAR parameters and the innovation matrix and has a $X^{1}(6)$ distribution.In Panel $D$, the Cumby-Huizinga (1992) 1-test for serial correlation of the residuals is robust to conditional beteroskedasticity and lagged dependent variables. The Q2-test is the LjungBox test statistic applied to squared residuals. The ARCH-test is the standard Lagrange multiplier test for serial correlation in the squared residuals, as proposed by Engle (1982). All tests are $x^{\mathbf{1}}(\mathrm{n})$ pith o the number of lagged squared residuals included in the test $\mathrm{Ku}$ is the normalized kurtosis coefficient and Sk the normalized skewness coefficient. Their asymptotic distribution is $N(0,24 / T), N(0,6 / T)$ respectively, with $T$ the sample size, under the null of normality. BJ is the Bera-Jarque (1982) test for normality and is $\chi^{2}(2)$. P-values, based on the $x^{2}$-distribution, are reported for all test statistics.

Panel A: Autocorrelationg

\begin{tabular}{|c|c|c|c|c|}
\hline & $\Delta_{0} \ln \left(M_{L}\right)$ & $\Delta \ln (x)$ & $\Delta_{2} \ln \left(N_{i}, 1\right)$ & $\Delta_{0} \ln \left(\gamma_{2}\right)$ \\
\hline 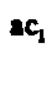 & $\begin{array}{c}.464 \\
(.102)\end{array}$ & $\begin{array}{c}296 \\
(.128)\end{array}$ & $\begin{array}{c}322 \\
(.167)\end{array}$ & $\begin{array}{c}376 \\
(.119)\end{array}$ \\
\hline $\operatorname{sc}_{2}$ & $\frac{255}{(.080)}$ & $\begin{array}{c}.067 \\
(.104)\end{array}$ & $\begin{array}{c}.439 \\
(.120)\end{array}$ & $\begin{array}{r}.143 \\
(.095)\end{array}$ \\
\hline$a c_{3}$ & $\begin{array}{c}345 \\
(.078)\end{array}$ & $\begin{array}{c}.139 \\
(.100)\end{array}$ & $\begin{array}{l}-.002 \\
(.119)\end{array}$ & $\begin{array}{l}. .102 \\
(.192)\end{array}$ \\
\hline$\Delta c_{4}$ & $\begin{array}{l}.118 \\
(.163)\end{array}$ & $\begin{array}{c}284 \\
(.117)\end{array}$ & $\frac{.238}{(.222)}$ & $\begin{array}{l}. .130 \\
(.150)\end{array}$ \\
\hline
\end{tabular}

Panel B: Selection ortteria for the VAR order

VAR order Akaike criterion Schwarz criterion

$1 \quad-40.34 \quad-39.80$

$2 \quad-40.03 \quad-38.95$

$3 \quad-40.28 \quad-38.64$ 
Panel C: Parameter coefficleots for VAR of order 1

\begin{tabular}{|c|c|c|c|c|c|c|}
\hline & $\Delta_{2} \ln \left(M_{i-1,2}\right)$ & $\Delta_{\Delta} \ln \left(x_{-1,0}\right)$ & $\Delta_{\Omega} \ln \left(N_{t-1,2}\right)$ & $\Delta_{1} \ln \left(Y_{t-1,2}\right)$ & $\mathbf{R}^{2}$ & Wald \\
\hline$\Delta_{\Delta} \ln \left(M_{\omega}^{0}\right)$ & $\begin{array}{c}537 \\
(.121)\end{array}$ & $\begin{array}{l}-.297 \\
(.194)\end{array}$ & $\begin{array}{r}-.068 \\
(.123)\end{array}$ & $\begin{array}{l}-.066 \\
(.102)\end{array}$ & 212 & $\begin{array}{l}6.008 \\
(.111)\end{array}$ \\
\hline$\Delta_{-} \ln \left(x_{0}\right)$ & $\begin{array}{c}.158 \\
(.068)\end{array}$ & $\begin{array}{c}204 \\
(.142)\end{array}$ & $\begin{array}{c}.087 \\
(.100)\end{array}$ & $\begin{array}{c}.050 \\
(.065)\end{array}$ & .091 & $\begin{array}{l}7.078 \\
(.069)\end{array}$ \\
\hline$\Delta_{\Delta} \ln \left(N_{L}\right)$ & $\begin{array}{l}-.012 \\
(.137)\end{array}$ & $\begin{array}{l}-.286 \\
(.175)\end{array}$ & $\begin{array}{c}289 \\
(.149)\end{array}$ & $\begin{array}{c}.097 \\
(.083)\end{array}$ & .097 & $\begin{array}{l}14.749 \\
(.002)\end{array}$ \\
\hline$\Delta_{\infty} \ln \left(y_{\omega} \omega\right)$ & $\begin{array}{l}-.425 \\
(.164)\end{array}$ & $\begin{array}{c}656 \\
(300)\end{array}$ & $\begin{array}{c}275 \\
(.164)\end{array}$ & $\begin{array}{l}-.092 \\
(.135)\end{array}$ & .152 & $\begin{array}{l}16.535 \\
(.001)\end{array}$ \\
\hline
\end{tabular}

Test on Innovation covariances: 17.793 (.007)

Panel D: Residual Dlagnostics

\begin{tabular}{llllccc}
\hline & $1(4)$ & Q2(4) & ARCH(4) & Ku & SK & BJ \\
\hline Eq. 1 & 6.825 & 3.876 & 3.922 & 265 & -.137 & 386 \\
& $(.145)$ & $(.423)$ & $(.417)$ & $(.665)$ & $(655)$ & $(.824)$ \\
Eq. 2 & 12462 & 7.902 & 8.746 & .973 & 296 & 3.459 \\
& $(.014)$ & $(.095)$ & $(.068)$ & $(.112)$ & $(.333)$ & $(.177)$ \\
Eq. 3 & 1.371 & 3.081 & 3.938 & .631 & -.370 & 2.520 \\
& $(849)$ & $(544)$ & $(.415)$ & $(303)$ & $(.277)$ & $(284)$ \\
Eq. 4 & 10.613 & 4.912 & 5.704 & .140 & .005 & .052 \\
& $(.031)$ & $(296)$ & $(202)$ & $(819)$ & $(.986)$ & $(.974)$
\end{tabular}


Tuble 3

GMM estlmation of the law of motlon for the forcing processes

The parameters estimated govern the unconditional moments of the law of motion specified in Equation (23) in the text. Although the Cholesky-decomposition of the unconditional covariance matrix of the innovations is estimated, I report the resulting correlation matrix of the inovations with standard deviations on the diagonal. The standard errors are obtained from the standard errors of the estimated parameters using the Mean Value Theorem. By estimating the Cholesty-decomposition directly, positive semi-definiteness of the covariance matrix is automatically imposed. The $\mathrm{J}_{\mathrm{T}}$ statistic tests the over-identifying restrictions of the original estimation with 16 moments. P-values are given in pareatheses. The C-tests test various restriations implied by the weekly model for quarterly date These restrictions are disoussed in the text The test methodology follows Eichenbaum, Hansen and Singleton (1988). First, the parameters are re-estimated using the 8 moment conditions to be tested in addition to the 16 original moments. This yields $1 x^{2}(12)$ test statistic for the overidentifying restrictions, which is denoted by $J_{T}$ (12). Suilable partitions of the resulting weighting matrix are then used to estimate the model parameters with less moment conditions. The difference of the $J_{T}(12)$ lest statistic and the new test of the over-identifying restrictions is denoted by $C_{T}(a)$ with a the number of momeal conditions not used in the final estimation. Hence, $C_{T}(6)$ is the test statistic for the 6 cross-moment restrictions, $C_{T}(2)$ the test statistic for the consumption autocovariance restrictions and $C_{T}(8)$ tests all 8 restrictions simultaneously. All test statistio bave $x^{2}$-distributions with degrees of freedom equal to the number indicated between brackets.

Autocorrelation coefinclents

$t_{1.1}=.893(.031)$

$\Delta_{1,1}-865(.038)$

Correlatlon matrix

$\begin{array}{cccc}.0003 & .291 & -.198 & -247 \\ (.00006) & (.128) & (.161) & (.107) \\ & .0015 & . .055 & 255 \\ & (.00014) & (.149) & (.128) \\ & .0004 & .465 \\ & (.00007) & (.114) \\ & & .0003 \\ & & (.00024)\end{array}$

Tests of the model

\begin{tabular}{llll}
\hline $\mathrm{J}_{\mathrm{T}}(4)$ & $\mathrm{C}_{\mathrm{T}}(8)$ & $\mathrm{C}_{\mathrm{T}}(6)$ & $\mathrm{C}_{\mathrm{T}}(2)$ \\
\hline 4.157 & 5.110 & 3.996 & 1.114 \\
$(385)$ & $(.746)$ & $(.6 \mathrm{~m})$ & $(573)$
\end{tabular}


Table 4

Simulation results for exchange rate changes and the forward premium

The simulated sample used in computing the endogenous model moments has $\mathbf{4 0 0 0}$ observations. Second order polynomials are used in approsimating the endogenous variables. The acronyms are understood as: CIA = casbin-advance, $A \mathrm{~L}=$ addilog $\mathrm{HO}=$ bomothetic $\mathrm{T}=$ time-additive, $\mathrm{D}=$ Durability, $\mathrm{DH}=$ durability and habit persistence. The beochmark parameters for DHAL are $B=97^{3 / 2}, \eta_{2}=\eta_{3}=.75, \theta_{2}=\theta_{y}=95, \mu_{2}=\mu_{y}=.76, c_{2}=c_{3}=.090$, $\xi_{x}=\xi_{y}=25, \gamma=02$. The benchmark parameters for DHHO are $B=99^{i m}, \eta_{1}=\eta_{y}=.75, \theta_{1}=\theta_{y}, 95, \mu_{2}=\mu_{x}=.76$, $C_{2}=C_{1}=.090, \xi_{1}=\xi_{y}=25, \gamma=1.1, \delta=5$. The first column repeats the data moments and their GMM based standard ertors. The next 3 columns of the table contain simpler variations of the benchmark specification, for ecample TAL in Panel A denotes a time-additive model $\left(\eta_{1}=\eta_{y}=0.0, \mu_{2}=\mu_{y}=0.0\right)$ with addilog preferences and a curvature parameter equal to 2 The $b_{1}$ and $a$ parameters $(i=1,2,3,4)$ in the far-rigbt column are the parameters governing the time-variation in the second moments of the forcing processes as specified in Equation (19) in the tex. The forcing processes are generated according to the estimated parameters of Table 3 and with conditional beteroskedasticity as determined by $b_{1}$ and $c_{r}$. For any simulation with conditional beteroskedasticity, polynomial elements with a higher than 99 correlation with other polynomial elements are discarded in order to reduce the dimensionality of the system. Panel A reports results for addilog preferences, Panel B for homothetic preferences and Panel $C$ for addilog preferences at the benchmark parameters but with $\gamma$ set equal to 2 . The last three columns in Panel $C$ report simulations for more extreme parameter values. In EXP I, $\theta_{2}$ and $\theta$, are set equal to 97 , but the other parameters are the ones from the full model with $\gamma=20$. In EXP II, there is no conditional beteroskedasticity $\left(b_{1}-q_{1}-0\right)$, but $\gamma=22 ; \eta_{1}=\eta_{y}=80$ and $\theta_{x}=\theta_{y}=98$. In EXP III, the parameters are the same as in EXP II but with the beochmark case conditional beteroskedasticity.

Panel A: Addliog preferences

\begin{tabular}{|c|c|c|c|c|c|c|}
\hline & DATA & CLA & TAL & DAL & DHAL & $\begin{array}{l}\text { DHAL } \\
b_{1}=80 \\
c_{1}=.13\end{array}$ \\
\hline$\sigma(\Delta \mathbf{s})$ & $\begin{array}{l}17.668 \\
(1.069)\end{array}$ & 2.825 & 4.091 & 4.180 & 4.280 & 4.366 \\
\hline$v_{13}(\Delta s)$ & $\begin{array}{l}1304 \\
(.133)\end{array}$ & 1.653 & 1.084 & 1.059 & 1.077 & 1.050 \\
\hline$v_{s n}(\Delta s)$ & $\begin{array}{l}1.725 \\
(314)\end{array}$ & 1.995 & 1.044 & 1.006 & 978 & 1.084 \\
\hline$\sigma\left(f_{p}\right)$ & $\begin{array}{l}3.481 \\
(343)\end{array}$ & 3.812 & .446 & .646 & .909 & 1.019 \\
\hline$v_{13}\left(f_{p_{b}}\right)$ & $\begin{array}{l}12350 \\
(390)\end{array}$ & 8.142 & 1.176 & 2761 & 3.905 & 5.433 \\
\hline$v_{s D}\left(f_{P_{S}}\right)$ & $\begin{array}{l}32.798 \\
(3.667)\end{array}$ & 12320 & 1.245 & 3.242 & 4.926 & 8.858 \\
\hline$\sigma\left(P_{,}\right)$ & $\begin{array}{l}10841 \\
(2847)\end{array}$ & .002 & .005 & .003 & .005 & .011 \\
\hline
\end{tabular}


Panel B: Homothetic preferences

\begin{tabular}{|c|c|c|c|c|c|c|}
\hline & DATA & CLA & TAHO & DAL & DHAL & $\begin{array}{l}\text { DHAL } \\
b_{i}=.80 \\
c_{1}=.13\end{array}$ \\
\hline$\sigma(\Delta s)$ & $\begin{array}{l}17.668 \\
(1.069)\end{array}$ & 1304 & 4.933 & 4.901 & 6.385 & 6.911 \\
\hline$v_{1 J}(\Delta s)$ & $\begin{array}{l}1.304 \\
(.133)\end{array}$ & 8.140 & 1.037 & 1.041 & .948 & .992 \\
\hline$v_{m}(\Delta s)$ & $\begin{array}{l}1.725 \\
(314)\end{array}$ & 12439 & 1.015 & 1.024 & .762 & .746 \\
\hline$\sigma\left(\mathfrak{f}_{\mathrm{P}_{W 1}}\right)$ & $\begin{array}{l}3.481 \\
(343)\end{array}$ & 3.757 & .474 & .674 & 1.794 & 2.246 \\
\hline$v_{13}\left(f_{p_{1}}\right)$ & $\begin{array}{l}12350 \\
(390)\end{array}$ & 8.115 & 1.132 & 3.168 & 9303 & 8.558 \\
\hline$v_{50}\left(f_{p_{4}}\right)$ & $\begin{array}{l}32.798 \\
(3.667)\end{array}$ & 12345 & 1.221 & 3.532 & 20,552 & 17.242 \\
\hline$\sigma\left(\mathrm{P}_{\mathrm{Q}}\right)$ & $\begin{array}{r}10841 \\
(2847)\end{array}$ & .001 & .003 & .005 & .009 & .025 \\
\hline
\end{tabular}

Panel C: Addilog preferences with $\gamma=2$

\begin{tabular}{|c|c|c|c|c|c|c|c|c|c|}
\hline & DATA & CIA & TAL & DAL & DHAL & $\begin{array}{l}\text { DHLAL } \\
b_{1}=.80 \\
c_{1}=.13\end{array}$ & $\begin{array}{c}\text { EXP } \\
I\end{array}$ & $\begin{array}{c}\text { EXP } \\
\text { II }\end{array}$ & $\begin{array}{c}\text { EXP } \\
\text { III }\end{array}$ \\
\hline$o(\Delta s)$ & $\begin{array}{l}17.668 \\
(1.069)\end{array}$ & 4.159 & 7544 & 7541 & 12.650 & 13.923 & 17583 & 27.831 & 41.617 \\
\hline$v_{13}(\Delta s)$ & $\begin{array}{l}1304 \\
(.133)\end{array}$ & 2314 & 1.038 & 1.032 & .907 & 970 & .987 & .978 & .995 \\
\hline$v_{s}(\Delta s)$ & $\begin{array}{l}1.725 \\
(314)\end{array}$ & 3.111 & 1.048 & 1045 & .622 & .614 & .661 & .700 & $\$ 92$ \\
\hline$\sigma\left(f_{p}\right)$ & $\begin{array}{l}3.481 \\
(343)\end{array}$ & 3.731 & .685 & 865 & 3.903 & 4.953 & 6.279 & 9540 & 14.781 \\
\hline$v_{13}\left(f p_{44}\right)$ & $\begin{array}{l}12350 \\
(390)\end{array}$ & 7.952 & 1.176 & 3.421 & 10.009 & 9.049 & 9.139 & 11.126 & 8.670 \\
\hline$v_{s y}\left(f_{p_{64}}\right)$ & $\begin{array}{l}32.798 \\
(3.667)\end{array}$ & 12.161 & 1.224 & 3.825 & 22.620 & 18.683 & 20.712 & 30.057 & 21.201 \\
\hline$\sigma\left(\mathrm{P}_{4}\right)$ & $\begin{array}{l}10.841 \\
(2.847)\end{array}$ & .003 & .006 & .011 & .041 & .183 & 363 & 376 & 4.608 \\
\hline
\end{tabular}




\section{Table 5}

Heteroskedastleity and fat tails in the endogenous variables

See Tables 1 and 4 for an explanation of the symbols used in this table.

Panel A: Addllog Preferences

\begin{tabular}{|c|c|c|c|c|c|c|}
\hline & DATA & CIA & TAL & DAL & DHAL & $\begin{array}{l}\text { DHAL } \\
b_{1}=.80 \\
c_{1}=.13\end{array}$ \\
\hline $\operatorname{kv}(\Delta s)$ & $\begin{array}{c}3.000 \\
(1.290)\end{array}$ & .012 & -.027 & -.042 & .156 & .652 \\
\hline$v_{13}\left((\Delta s)^{2}\right)$ & $\begin{array}{l}2419 \\
(.427)\end{array}$ & 1242 & 956 & .912 & 1.126 & 1.835 \\
\hline$v_{s}\left((\Delta s)^{2}\right)$ & $\begin{array}{l}4.101 \\
(.717)\end{array}$ & 1.185 & 871 & 816 & 1.262 & 2.771 \\
\hline$k u\left(\Delta f_{(A)}\right)$ & $\begin{array}{c}8.635 \\
(2495)\end{array}$ & .052 & .731 & 589 & 3.118 & 12.401 \\
\hline$v_{b}\left(\left(\Delta f_{p_{2}}\right)^{2}\right)$ & $\begin{array}{l}2718 \\
(.413)\end{array}$ & 1.157 & 1664 & 1.713 & 1.814 & 2.350 \\
\hline$v_{D 2}\left(\left(\Delta f p_{L 1}\right)^{2}\right)$ & $\begin{array}{c}5.957 \\
(1.174)\end{array}$ & 1335 & 1.574 & 1.743 & 2182 & 2.869 \\
\hline
\end{tabular}


Panel B: Homothetlc preferences

\begin{tabular}{|c|c|c|c|c|c|c|}
\hline & DATA & CLA & TAL & DAL & DHAL & $\begin{array}{l}\text { DHAl } \\
b_{1}=80 \\
c_{1}=.13\end{array}$ \\
\hline $\mathbf{k u}(\Delta \mathbf{s})$ & $\begin{array}{c}3.000 \\
(1.290)\end{array}$ & .040 & .010 & -.010 & .030 & .280 \\
\hline$v_{13}\left((\Delta s)^{2}\right)$ & $\begin{array}{l}2.419 \\
(.427)\end{array}$ & 7374 & 1.085 & 1.068 & 1.058 & 1.761 \\
\hline$v_{15}\left((\Delta s)^{2}\right)$ & $\begin{array}{l}4.101 \\
(.717)\end{array}$ & 10.150 & 937 & 948 & 885 & 2.574 \\
\hline $\mathbf{k u}\left(\Delta \mathrm{f}_{\mathrm{p}}\right)$ & $\begin{array}{c}8.635 \\
(2.495)\end{array}$ & -.011 & 3.015 & 3.347 & 3.056 & 5.198 \\
\hline$v_{B v}\left(\left(\Delta f_{p_{L A}}\right)^{2}\right)$ & $\begin{array}{r}2.718 \\
(.413)\end{array}$ & 1.030 & 1.934 & 1.693 & 1.793 & 2569 \\
\hline$v_{2}\left(\left(\Delta f_{p_{L}}\right)^{2}\right)$ & $\begin{array}{c}5.957 \\
(1.174)\end{array}$ & 968 & 1.990 & 1.889 & 2.028 & 3.531 \\
\hline
\end{tabular}

Panel C: Addilog preferences with more curvature

\begin{tabular}{|c|c|c|c|c|c|c|}
\hline & DATA & CIA & TAL & DAL & DHAL & $\begin{array}{l}\text { DHAL } \\
b_{1}=.80 \\
c_{1}=.13\end{array}$ \\
\hline $\mathbf{k} \mathbf{u}(\Delta \mathbf{s})$ & $\begin{array}{c}3.000 \\
(1.290)\end{array}$ & .031 & .020 & .047 & .128 &.$m 2$ \\
\hline$v_{12}\left((\Delta s)^{2}\right)$ & $\begin{array}{l}2.419 \\
(.427)\end{array}$ & 1.429 & 1.068 & 1.071 & 1.032 & 2.625 \\
\hline$v_{2}\left((\Delta s)^{2}\right)$ & $\begin{array}{l}4.101 \\
(.717)\end{array}$ & 1.373 & 869 & .909 & 901 & 4.461 \\
\hline$k v\left(\Delta f_{p_{W}}\right)$ & $\begin{array}{c}8.635 \\
(2.495)\end{array}$ & 249 & 3215 & 2.528 & 1543 & 6.363 \\
\hline$v_{\iota \jmath}\left(\left(\Delta f_{P_{W}}\right)^{2}\right)$ & $\begin{array}{l}2.718 \\
(.413)\end{array}$ & 1.289 & 2508 & 1.713 & 1.864 & 2385 \\
\hline$v_{s 2}\left(\left(\Delta f_{P_{4},}\right)^{2}\right)$ & $\begin{array}{c}5.957 \\
(1.174)\end{array}$ & 1.158 & 2946 & 1.934 & 1.933 & 3.224 \\
\hline
\end{tabular}


Figure 1: Sensitivity to $\gamma$ (Addilog Utility)

Figure 1a: Effect on Variability

$0\left(p_{1}\right)$

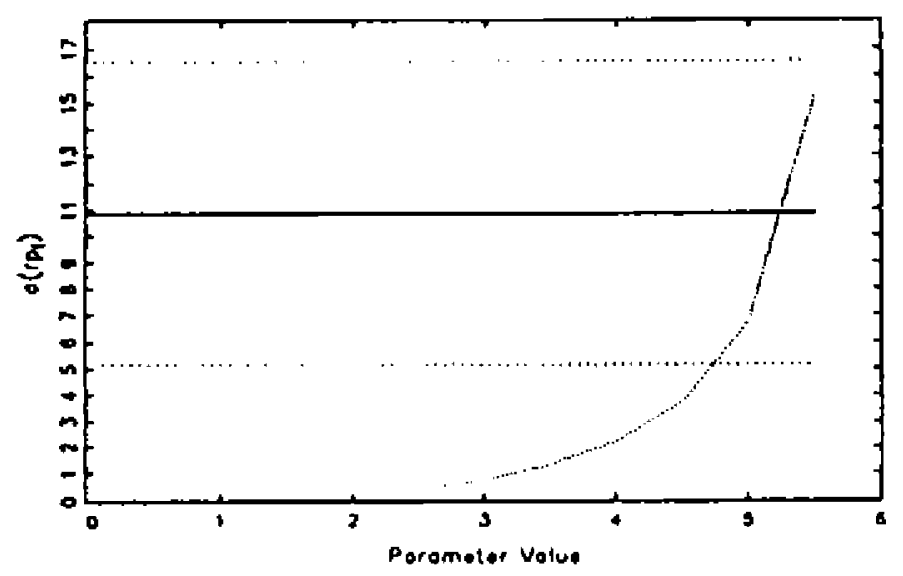

o(ID)

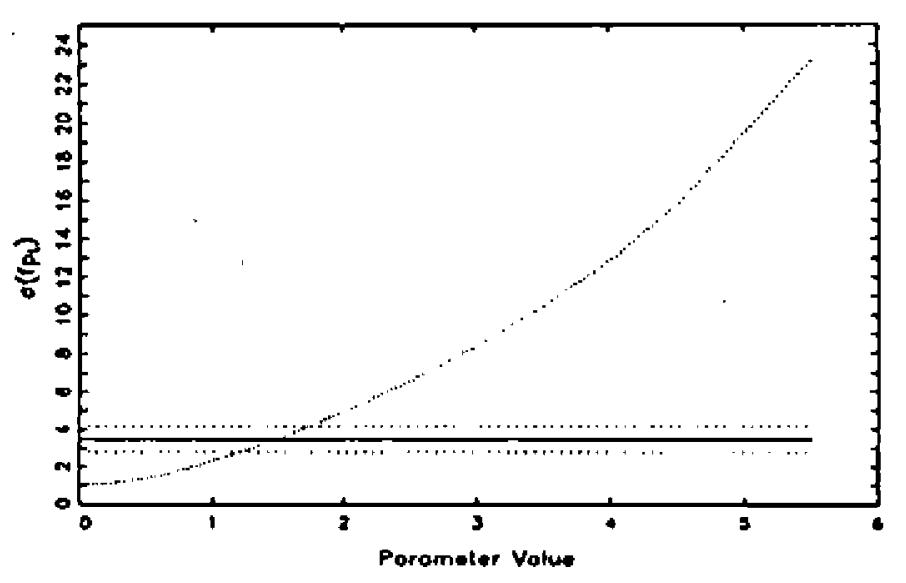

$\sigma(d=)$

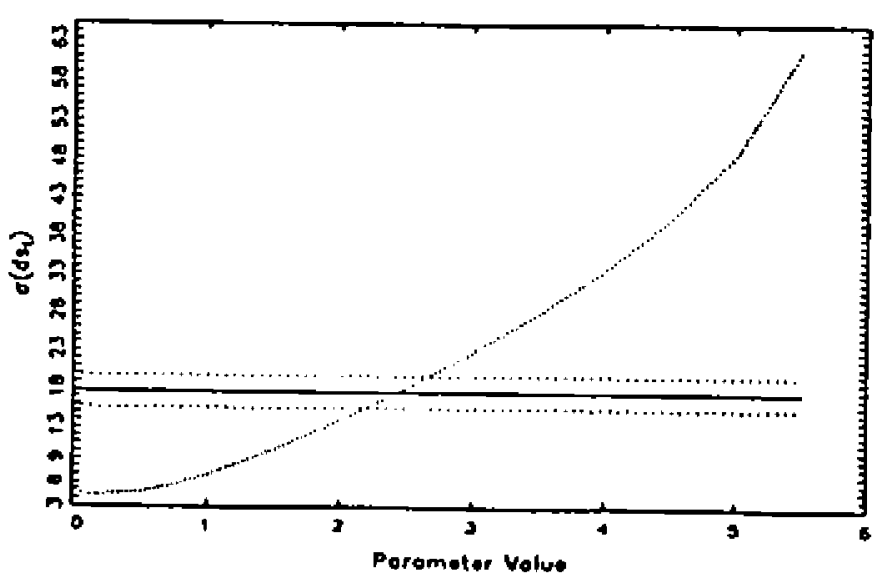


Figure 1b: Effect on Persistence
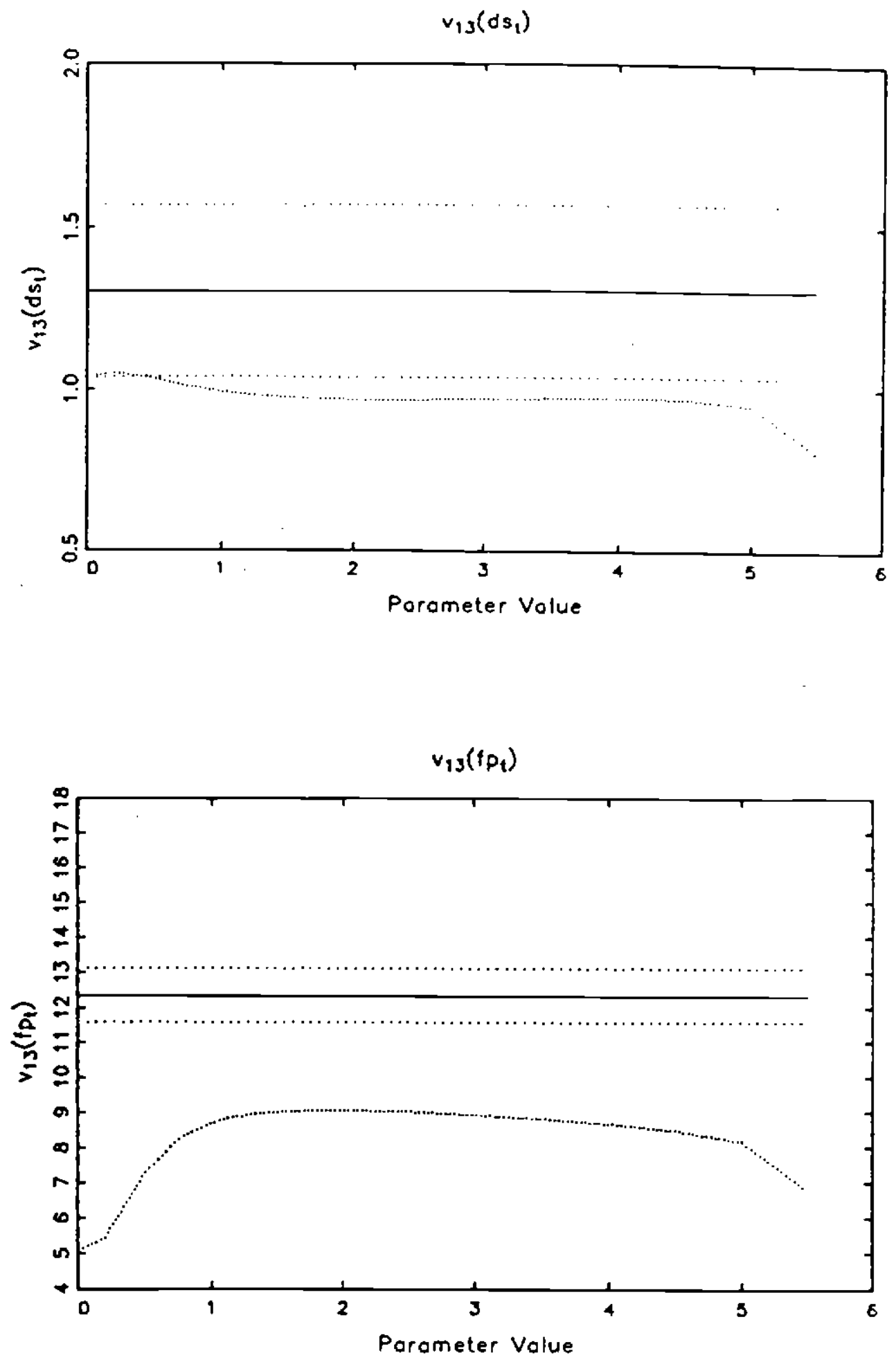
Figure 1c: Effect on Non-Linearities
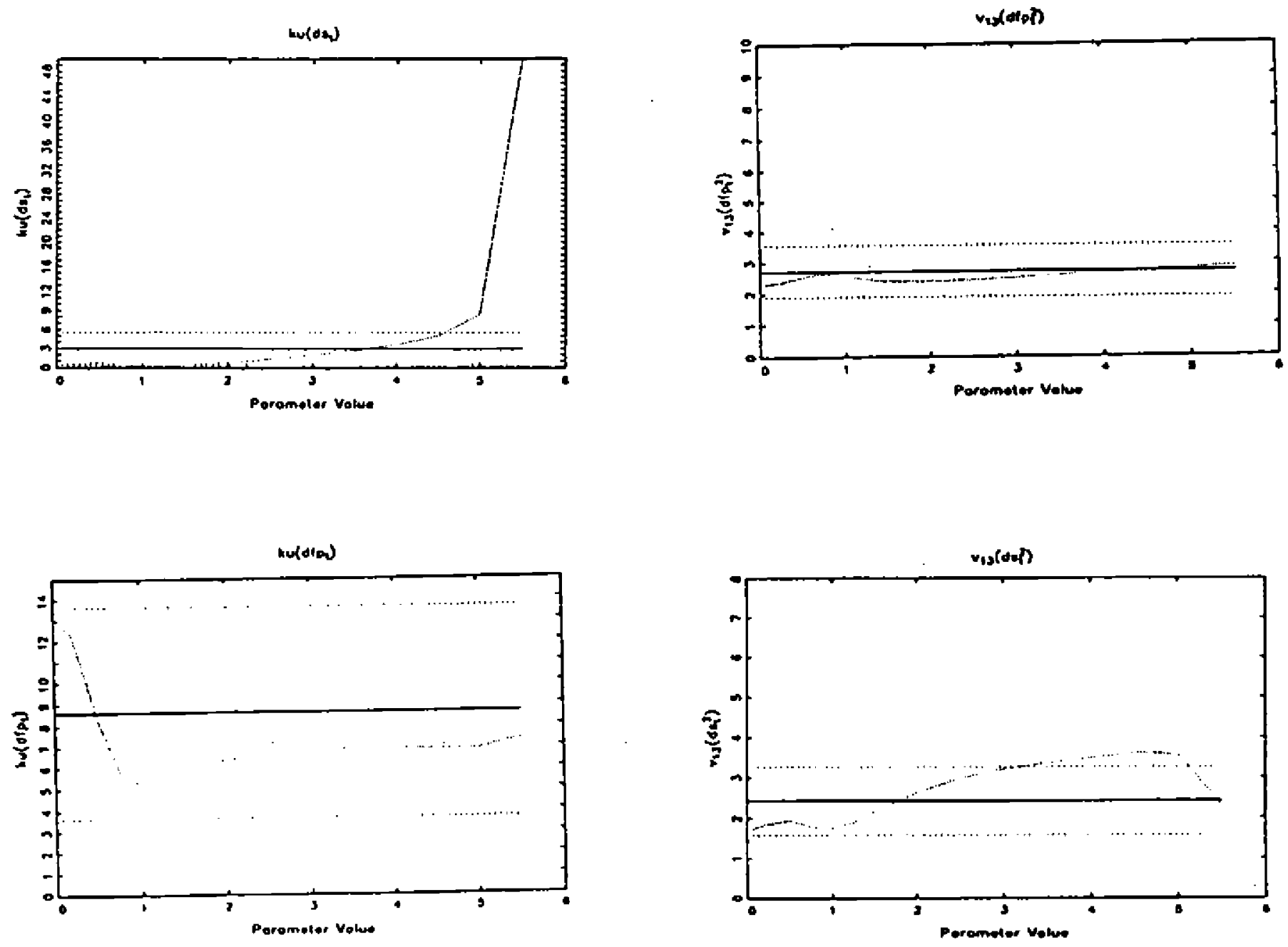